\title{
Rastros de contatos e grafos dinâmicos
}

\author{
Milson Silva Monteiro
}

Tese Apresentada

$\mathrm{AO}$

Instituto de MATEMÁticA e EstatísticA

DA

Universidade De SÃo Paulo

PARA

ObTEnÇÃo Do TÍtulo

DE

Doutor EM CiÊNCIAS

Programa: Pós-Graduação em Ciência da Computação

Orientador: Prof. Dr. Anatoli Iambartsev 


\section{Rastros de contatos e grafos dinâmicos}

Esta é a versão apresentada para a defesa de tese, elaborada pelo candidato Milson Silva Monteiro, tal como submetida à Comissão Julgadora. 


\section{Rastros de contatos e grafos dinâmicos}

Esta versão da tese contém as correções e alterações sugeridas pela Comissão Julgadora durante a defesa da versão original do trabalho, realizada em 15/12/2016. Uma cópia da versão original está disponível no Instituto de Matemática e Estatística da Universidade de São Paulo.

Comissão Julgadora:

- Prof. Dr. Anatoli Iambartsev (Orientador) - IME - USP

- Prof. Dr. Sofiane Ben El Hedi Labidi - UFMA

- Prof. Dr. Vladimir Belitsky - IME - USP

- Prof. Dr. Ricardo de Andrade Lira Rabêlo - UFPI

- Prof. Dr. Ronaldo Fumio Hashimoto IME - USP 


\section{Agradecimentos}

A Deus, pois sem Ele nada poderia ser feito.

Ao meu orientador, Prof $^{\circ}$ Dr. Anatoli Iambartsev pela paciência, diálogos, ensinamentos, fraternidade, singularidade e ideias que possibilitaram o desenvolvimento da pesquisa. É uma honra e privilégio ser seu orientando.

Aos meus pais, Bernardino Tavares Monteiro (in memoriam) e Maria Auta Silva Monteiro, pela minha formação profissional e por me ensinar o significado do amor gratuito.

Aos meus irmãos Milton Silva Monteiro, Monica Silva Monteiro e Maria Monica Silva Monteiro.

A tia Felizia (in memoriam) e aos primos Mary e Pedro pelo convívio constante e amizade.

Ao Instituto de Matemática e Estatística da Universidade de São Paulo, seu corpo docente, direção e administração por disponibilizar o ambiente e a infraestrutura necessária para o desenvolvimento da pesquisa.

A Coordenação do Programa de Pós-Graduação em Ciência da Computação e aos professores por possibilitar o desenvolvimento da pesquisa.

Ao amigo Prof ${ }^{\circ}$ Demerval Dias Ramos (in memoriam), sou eternamente grato.

A Lúcia de Fátima Brito Oliveira por sua delicadeza e amizade.

Ao Prof ${ }^{\circ}$ Dr. Zair Abdelouahab (in memoriam) pela amizade e diálogos constantes.

A Universidade Estadual do Maranhão, seu corpo docente, direção e administração que oportunizaram a liberação do meu afastamento para desenvolver o doutorado.

Ao Profo Dr. Alair Pereira do Lago pelos ensinamentos.

A atenção e disponibilidade do Profo Dr. Arnaud Casteigts em esclarecer questionamentos relacionados com grafos dinâmicos.

Ao Prof ${ }^{\circ}$ Dr. Antonio Pinto Neto pelo apoio e amizade sempre presente.

A Laila pelos diálogos e amizade.

Ao amigo John Lenon Gardenghi e família, pela delicadeza e convivência diária.

A constelação de amigos Renzo Gomez, Alexandre Martins, Jihan, José Theodoro, Diogo Pina, Rafael Will, Anderson Conceição, Jessica, Oberlan, Suzana Santos, Samuel Placa e Virginia Carrara.

A gentileza e atenção de todos os funcionários da Biblioteca do IME-USP.

A delicadeza e atenção de Alessandra Monteiro, Ronaldo Matayoshi e Cícero Wandenberg. 
A Lucileide pela delicadeza pela qual eu sempre fui recebido na Coordenação da PósGraduação do IME-USP.

A todos que contribuíram neste trabalho e fazem parte da minha vida, o meu agradecimento. 


\section{Resumo}

Com base em três modelos de mobilidade MapBasedMovement, RandomWayPoint e Random Walk presentes no simulador The One, sugerimos e discutimos vários modelos estocásticos para mobilidade. Primeiramente, a dinâmica das unidades móveis é reduzida a um processo chamado grafo dinâmico, de forma que a configuração espacial das unidades móveis em cada instante de tempo está resumida em um grafo. Os vértices desse grafo são unidades móveis e não mudam conforme o tempo: consideramos um sistema fechado, as unidades não desaparecem e não aparecem novas. O elo entre duas unidades (vértices) em um instante de tempo significa um contato neste instante (a distância entre as unidades é menor que um raio de contato), assim o conjunto de elos muda durante a evolução do sistema. Em seguida, modelamos a evolução do grafo dinâmico como um conjunto de processos aleatórios binários de forma que cada componente do processo está associada com um par de unidades móveis indicando presença ou ausência de contato entre elas. Três componentes principais constroem o processo: (i) distribuição de tempo de intercontato, (ii) distribuição de tempo de contato, e (iii) independência/interação entre as unidades. Nesta Tese mostramos teoricamente e através de simulações como escolher todos os três componentes para três modelos de mobilidade mencionados acima na situação de baixa densidade de unidades móveis, chamado DTNs (Delay Tolerant Networks). Considerar a modelagem da mobilidade desse ponto de vista é novo e não existe na literatura, até onde sabemos. Existe uma discussão na literatura sobre o tempo de intercontato, mas não conhecemos os resultados e discussão sobre a distribuição do tempo de contato e a interdependência de processos de contatos.

Palavras-chave: modelos de mobilidade. grafos dinâmicos. redes DTNs. modelagem de mobilidade. distribuição do tempo de contato. interdependência de processos de contatos. 


\section{Abstract}

Based on three mobility models MapBasedMovement, RandomWayPoint and Random Walk present on The One Simulator we suggest and discuss various stochastic models for mobility. First the dynamics of mobile units is reduced to process called dynamic graph, so that the spatial configuration of mobile units in every moment of time is summed up in a graph. The vertices of this graph are mobile units and do not change with the time: consider a closed system, the units don't disappear and not appear new. The link between two units (vertices) in an instant of time means a contact right now (distance between the units is less that the radius contact). So the set of links changes during the system evolution. As a second step, the evolution of dynamic graph model as a set of random processes. Each process component is associated with a pair of mobile units indicating presence or absence of contact between them. Three major components build process: (i) distribution of intercontact time, (ii) distribution of contact time, and (iii) Independence interaction between units. In this work we show theoretically and by simulation how to choose all three components for three mobility models mentioned above on the situation of low density of mobile units, called DTNs (Delay Tolerant Networks). Consider the mobility modeling from that point of view is new and does not exist in the literature for our knowledge. There is a discussion in the literature about the intercontact time, but we don't know the results and discussion on the distribution of contact time and the interdependence of contact process.

Keywords: mobility models. dynamic graphs. DTNs networks. mobility modeling. distribution of contact time. interdependence of contact process. 


\section{Sumário}

Lista de Figuras $\quad$ ix

Lista de Tabelas $\quad$ xi

1 Introdução e Motivação 1

2 Simulador The One, Grafo Dinâmico. $\quad 7$

2.1 Simulador The One. . . . . . . . . . . . . . . . . . . . . 7

2.2 Modelos de mobilidade no ecossistema das redes DTNs . . . . . . . . . . 10

2.3 Grafos Dinâmicos . . . . . . . . . . . . . . . . . . . . . 11

3 Distribuição dos tempos de contato e intercontato 13

3.1 Tempo de intercontato . . . . . . . . . . . . . . . . . . . . . . 13

3.1.1 Tempo de intercontato mobilidade Random WayPoint. . . . . . . . 16

3.1.2 Tempo de intercontato mobilidade Random Walk. . . . . . . . . . 18

3.1.3 Tempo de intercontato MapBasedMovement. . . . . . . . . . . . . 22

3.2 Tempo de Contato . . . . . . . . . . . . . . . . . . . 22

3.2.1 Modelo matemático da distribuição do tempo de contato. . . . . . 22

3.2 .2 Resultados da simulação . . . . . . . . . . . . . . . . . . . . . . . 24

4 Grafo dinâmico como processo estocástico $\quad 27$

4.1 Grafo dinâmico markoviano . . . . . . . . . . . . . . . . 27

4.1 .1 Primeiro Cenário . . . . . . . . . . . . . . . . . . . 28

4.1 .2 Segundo Cenário . . . . . . . . . . . . . . . . . . . . . . . 29

4.2 Grafo dinâmico como processo de renovação . . . . . . . . . . . . . . . . 29

5 Métricas de redes complexas aplicadas no grafo dinâmico (evolução temporal)

5.1 Cenário de aplicação das métricas de redes complexas do grafo dinâmico 33

6 Conclusão $\quad 39$

6.1 Trabalhos Futuros . . . . . . . . . . . . . . . . . . 40

Referências Bibliográficas $\quad 41$ 


\section{Lista de Figuras}

2.1 Componentes do simulador The One. Fonte: (Mayer, 2012). . . . . . . . 8

2.2 Arquitetura do arcabouço para aquisição de dados do grafo dinâmico. . . 9

2.3 Exemplo de grafo dinâmico de intervalo de tempo discreto associado com um cenário de mobilidade de um rastro de contatos DTNs. . . . . . . . . 12

3.1 Resultados dos cenários de intercontatos dos modelos de mobilidade (MapBasedMovement, Random Walk e Random Waypoint). . . . . . . . . . . . . 16

3.2 Resultados dos cenários de simulação do modelo random walk no torus unidimensional para diferentes tamanhos do torus: 100, 1000 e $10^{4}$. . . .

3.3 Resultados dos cenários de simulação do modelo random walk no torus bidimensional para diferentes tamanhos do torus: $100 \times 100,1000 \times 1000$. . 21

3.4 Modelo de percurso livre de duas unidades móveis. . . . . . . . . . . . . 22

3.5 Modelo de percurso livre de duas unidades móveis. . . . . . . . . . . . . . 23

3.6 Resultados dos cenários de simulação de contatos dos modelos de mobilidade (map based movement, random walk e random waypoint). . . . . .

5.1 Exemplo de três snapshots de um grafo dinâmico de intervalo de tempo discreto. . . . . . . . . . . . . . . . . . .

5.2 Evolução temporal da aplicação das métricas de redes complexas no grafo dinâmico usando o simulador independente e o simulador The One para o modelo de mobilidade map based movement. . . . . . . . . . . . . . . . .

5.3 Evolução temporal da aplicação das métricas de redes complexas no grafo dinâmico usando o simulador independente e o simulador The One para o modelo de mobilidade random walk. . . . . . . . . . . . . . . . .

5.4 Evolução temporal da aplicação das métricas de redes complexas no grafo dinâmico usando o simulador independente e o simulador The One para o modelo de mobilidade random waypoint. . . . . . . . . . . . . 
$\mathrm{x}$ LISTA DE FIGURAS 


\section{Lista de Tabelas}

5.1 Resultados dos cálculos da aplicação das métricas . . . . . . . . . . . 33

5.2 Configuração dos parâmetros para os cenários de mobilidade Map Based Movement, Random Walk e Random Waypoint. . . . . . . . . . . . . . . 33 


\section{Capítulo 1}

\section{Introdução e Motivação}

No contexto da computação móvel, podemos descrever um sistema de comunicação como uma topologia lógica com características de auto-organização que possibilita conectar diversos componentes (unidades móveis) utilizando um conjunto de regras denominado protocolo de comunicação. Atualmente, as principais redes da computação móvel utilizadas para o desenvolvimento de pesquisas são as redes Ad Hoc, MANETs (Mobile Ad Hoc Networks) e as redes DTNs (Delay Tolerant Networks) que apresentamos a seguir as suas principais características.

As redes $A d H o c$ são redes hierárquicas e descentralizadas composta por unidades móveis que possuem propriedades de auto-organização e funcionam como roteadores. Para estabelecer uma sessão de comunicação entre as unidades móveis fonte e destino as redes $A d$ Hoc usam o mecanismo de difusão para compartilhar um único canal de comunicação para enviar ou receber mensagens. Nas redes Ad Hoc como as mudanças de topologia não são frequentes, geralmente são usados algoritmos de descoberta de topologia [Roy10, SBP13, LMO11, SGS15].

As MANETs (Mobile Ad Hoc Networks) são sistemas autônomos e descentralizados que apresentam redes com alta densidade de nós. Desta forma, os nós móveis podem estabelecer uma sessão de comunicação utilizando o mecanismo de difusão para realizar o roteamento das mensagens sem a necessidade de um ponto de acesso. É imperativo no modelo de comunicação em MANETs que exista um enlace de comunicação direto entre as unidades móveis fonte e destino [Roy10, SGS15].

As redes DTNs (Delay and Disruption Tolerant Networks) são ecossistemas de comunicação autônomos e descentralizados que apresentam topologia esparsa com baixa densidade de unidades móveis que usam o mecanismo de comutação para executar o roteamento das mensagens entre as unidades móveis fonte e destino. Deste modo, os modelos de mobilidade exercem grande influência na topologia da rede do ecossistema DTN, sendo comum que exista intermitência das conexões, condições ambientais extremas (ambientes hostis em que a comunicação e a movimentação são comprometidas), longos períodos de latência, ruídos e ausência de garantia da existência de um caminho 
fim a fim [KAF12, FF08, dSBHO15, CR13, Zha06].

O projeto das redes DTNs teve origem na NASA (National Aeronautics and Space Administration) para desenvolver tecnologias de comunicação para propagar informações nas atividades de missões espaciais e o projeto da internet interplanetária [FF08]. Nesta perspectiva, Kevin Fall observou que as ideias do ecossistema das redes DTNs poderiam ser aplicadas às redes terrestres que apresentam cenários e desafios semelhantes aos relacionados com as características que foram elencadas anteriormente. Neste contexto, a mobilidade é um tema emergente de pesquisa que visa compreender as interações entre as unidades móveis enquanto estão desenvolvendo o processo de comunicação em ecossistemas DTNs. Desta forma, para desenvolver a avaliação de desempenho destes ecossistemas com acurácia é imperativo a análise sistemática de modelos de mobilidade.

A tecnologia utilizada nos ecossistemas das redes DTNs apresentam várias questões em aberto ou em reformulação associadas com as unidades móveis de ecossistemas DTNs para abordar o problema da mobilidade, encontros casuais e as transmissões oportunistas. A avaliação de desempenho de protocolos utilizados nestes ecossistemas relacionados com a mobilidade auxilia a prever o seu comportamento e desempenho em diferentes cenários e configurações relacionadas com as unidades móveis (sementes, tempo de pausa, velocidade, quantidade e raio). Enquanto, os sistemas Ad Hoc e MANETs são modelos de redes bem estudados na literatura e desenvolvidos na prática a avaliação de desempenho de ecossistemas DTNs é um problema em aberto que está diretamente relacionada com a modelagem matemática e as variações frequentes que ocorrem na topologia da rede provenientes da influência da mobilidade, e que estão intrinsecamente relacionadas com as condições ambientais e climáticas adversas.

A motivação para o desenvolvimento desta tese visa analisar em sílico três ecossistemas DTNs (MapBasedMovement, RandomWalk e RandomWayPoint) relacionado com a mobilidade, que possibilita auxiliar na criação de projetos de avaliação de desempenho de protocolos de comunicação para redes DTNs. Na literatura existem trabalhos que relatam a importância da mobilidade na avaliação de desempenho do ecossistema das redes DTNs, e os modelos de mobilidade são empregados para impor restrições sobre a movimentação das unidades móveis e os rastros de contatos fazem o registro dos encontros mútuos destas unidades [CR13, CS13, Zha06, FF08]. Neste contexto, a pesquisa preenche uma lacuna na literatura sobre o fenômeno da mobilidade em ecossistemas DTNs e possui relevância teórica.

Para sistematizar o processo da análise de modelos de mobilidade, usamos rastros de contatos que registram as oportunidades de encontros mútuos diretos ou indiretos das unidades móveis em ecossistemas DTNs (sintéticos ou reais). A análise da mobilidade com este propósito é extremamente complexa, porém utilizamos modelos de mobilidade e aplicamos métricas que sejam independentes da tecnologia da rede móvel que possibilita a aquisição de dados dos rastros de contatos DTNs. Os rastros de contatos podem ser descritos através de grafos dinâmicos [CKNP15]. A aplicação das métricas de redes no 
grafo dinâmico possibilita coletar dados para desenvolver a análise estatística dos experimentos relacionados com os modelos de mobilidades de ecossistemas de redes DTNs. Neste contexto, utilizamos o conjunto de dados resultantes da aplicação das métricas para desenvolver a análise estatística dos rastros de contatos relacionado com a mobilidade das unidades móveis.

Grafo dinâmico. A tese aborda a questão da modelagem teórica (matemática) de três tipos de modelos de mobilidade. Os modelos representam (resumem) a dinâmica de $N$ unidades móveis em uma área finita $A$ como uma dinâmica estocástica de grafo dinâmico

$$
\mathcal{G}=\left(G_{t}, t=0,1,2, \ldots, T\right)
$$

de tempo discreto $t=0,1, \ldots, T$, em que para cada instante $t$ fixo $G_{t}=\left(V, E_{t}\right)$ é um grafo com os vértices $V$ que são unidades móveis enumeradas $V=\{1,2, \ldots, N\}$, e um elo entre duas unidades móveis $i, j, i \neq j$ esteja presente no grafo $G_{t}$, isto é $(i, j) \in E_{t}$, se e somente se entre essas unidades existe um contato, ou seja, a distância entre as unidades é menor que dois raios de contato. Assim a posição de unidades móveis na área, a velocidade delas e outras características da dinâmica da rede DTN é perdida nesta transição da dinâmica da rede para a dinâmica do grafo dinâmico.

Como um grafo $G$ qualquer pode ser representado e definido através de uma matriz de adjacência $\mathcal{A}(G)=\left(a_{i j}, i, j=1, \ldots, N\right)$, então a dinâmica do grafo $\left(G_{t}\right)$ é dinâmica dessa matriz

$$
\mathcal{A}_{t} \equiv \mathcal{A}\left(G_{t}\right)=\left(a_{i j}(t), i, j=1, \ldots, N\right), t=0,1, \ldots, T
$$

o que em sua vez é representada como dinâmica binária de cada componente da matriz $a_{i j}(t) \in\{0,1\}$ para o par $i, j, i \neq j$ quaisquer. Assim, do ponto de vista de processos estocásticos, a evolução de grafo de contatos pode ser representado como um processo aleatório de uma matriz $\left(a_{i j}(t), i \neq j, i, j=1, \ldots, N\right)$ com componentes binários no conjunto (espaço de estados do processo)

$$
\left(a_{i j}(t), i \neq j, i, j=1, \ldots, N\right) \in\{0,1\}^{\left(\begin{array}{c}
N \\
2
\end{array}\right)} .
$$

Note que essa representação vale para qualquer processo de contatos. As redes DTN são caracterizadas com baixa densidade de unidade móveis na área $A$ :

$$
\frac{N}{\operatorname{vol}(A)} \ll 1,
$$

o que não influencia na representação da evolução da rede como um grafo dinâmico.

Construção do processo. Para definir de forma explícita o processo multidimensional $\mathcal{A}\left(G_{t}\right)$ precisamos definir a distribuição conjunta dos componentes. Este trabalho está focado na seguinte construção da distribuição do processo. Três componentes principais definem a distribuição do processo $\mathcal{A}_{t}$ : 
(i) tempo de intercontato: para cada par $i, j, i \neq j$ a distribuição $F_{i j}$ (cumulativa) do tempo de intercontato, $T_{i j}$, é o intervalo de tempo durante o qual $a_{i j}(t)=0$ : se $a_{i j}\left(t_{0}\right)=1$ e $a_{i j}\left(t_{0}+1\right)=0$ para algum instante $t_{0}$, então

$$
T_{i j}:=\min \left\{k \geq 1: a_{i j}\left(t_{0}+k\right)=1\right\} .
$$

Para cada par $i, j, i \neq j$, a sequência dos tempos de intercontatos $\left\{T_{i j}^{(k)}\right\}$ consideramos como uma sequência de variáveis aleatórias independentes e identicamente distribuídas.

(ii) tempo de contato: para cada par $i, j, i \neq j$ a distribuição $G_{i j}$ do tempo de contato, $\tilde{T}_{i j}$, quando $a_{i j}(t)=1$ : se $a_{i j}\left(t_{0}\right)=0$ e $a_{i j}\left(t_{0}+1\right)=1$ para algum instante $t_{0}$, então

$$
\tilde{T}_{i j}:=\min \left\{k \geq 1: a_{i j}\left(t_{0}+k\right)=0\right\}
$$

Para cada par $i, j, i \neq j$, a sequência dos tempos de contatos $\left\{\tilde{T}_{i j}^{(k)}\right\}$ consideramos como uma sequência de variáveis aleatórias independentes e identicamente distribuídas.

(iii) independência: suposição sobre a independência entre os processos de diferentes componentes $a_{i j}(t), a_{k l}(t),(i, j) \neq(k, l), i, j, k, l \in V$ :

$$
P\left(a_{i j}(t)=b, a_{k l}(t)=c\right)=P\left(a_{i j}(t)=b\right) P\left(a_{k l}(t)=c\right),
$$

para quaisquer $b, c \in\{0,1\}$ e para qualquer instante $t \in\{0,1, \ldots, T\}$.

Neste trabalho definimos três componentes para cada modelo de mobilidade e usando os dados obtidos in silico através do simulador The One verificamos se os dados confirmam as hipóteses (i)-(iii) sobre os componentes do nosso processo.

A estrutura da tese é formada do seguinte modo:

No Capítulo 2, apresentamos o simulador The One e os modelos de mobilidade usados pelo simulador. Também representamos a arquitetura do arcabouço de redes que usa o simulador para aquisição dos dados dos rastros de contatos, e a construção do grafo dinâmico.

No Capítulo 3, discutimos a adequação de distribuições teóricas do tempo de intercontato e contato para o conjunto de dados fornecidos pelo simulador. Notamos que essa parte relacionada com o tempo de contato não encontramos na literatura, pois em geral supunha-se que o tempo de contato é muito menor do que o tempo de intercontato, mas na construção explícita do processo precisamos definir exatamente a distribuição desse tempo.

No Capítulo 4, propomos dois tipos de processos de grafos dinâmicos: processo Markoviano e o processo de renovação. Provamos os teoremas sobre o tempo médio de propagação da informação no processo Markoviano. Provamos também os seguintes resultados 
sobre o regime estacionário desses dois tipos de processos: no regime estacionário o grafo dinâmico comporta-se como o grafo de Erdös-Rényi. Os resultados teóricos representados neste capítulo são novos, embora não sejam difíceis.

No Capítulo 5 discutimos a adequação da suposição sobre a independência. Embora esta questão seja natural na modelagem de processos, mas nunca observamos na literatura, e consideramos os resultados desse capítulo como resultados novos, pelo nosso conhecimento de estado da arte. Faremos a análise descritiva utilizando a técnica de permutação, uma das técnicas de validação não paramétrica.

No Capítulo 6, apresentamos as conclusões e consideramos os problemas em abertos mencionados na tese, mas não resolvidos e descrevemos as direções de possíveis pesquisas nesta área. 


\section{Capítulo 2}

\section{Simulador The One, Grafo Dinâmico.}

\section{$2.1 \quad$ Simulador The One.}

Segundo Jain [Jai91], a técnica de simulação tem como objetivo reproduzir o comportamento de um modelo de sistema com vistas à sua compreensão e características. $\mathrm{O}$ uso da simulação no desenvolvimento da pesquisa possibilita obter respostas relacionadas com a mobilidade das unidades em ecossistemas DTNs.

A linguagem declarativa usada nos cenários de simulação proporciona configurar os diversos atributos de forma sistemática e controlada, in silico, para avaliar a mobilidade do ecossistema sob diferentes perspectivas.

É imperativo definir os atributos que são importantes ao utilizar simuladores para modelar ecossistemas DTNs relacionados com a mobilidade das unidades, como por exemplo: a semente, o modelo de mobilidade, a área geográfica, o raio de cobertura, a quantidade de unidades móveis e o tempo de pausa.

O uso de simulador oportunista proporciona reproduzir o comportamento dos cenários de ecossistemas DTNs com foco na aquisição de dados. Logo, a análise estatística deve ser desenvolvida sobre o conjunto de dados.

No desenvolvimento da pesquisa, utilizamos a técnica de simulação para gerar rastros de contatos relacionados com o modelo de mobilidade definido nos cenários [CR13, dSBHO15, KKO10, KOK09]. Esta atividade é importante e está relacionada com a complexidade da reprodução de um experimento dinâmico e a sua influência no padrão de conectividade da topologia de ecossistemas DTNs.

A Figura 2.1 apresenta os componentes do simulador The One para gerar os rastros de contatos DTNs [May12]. 


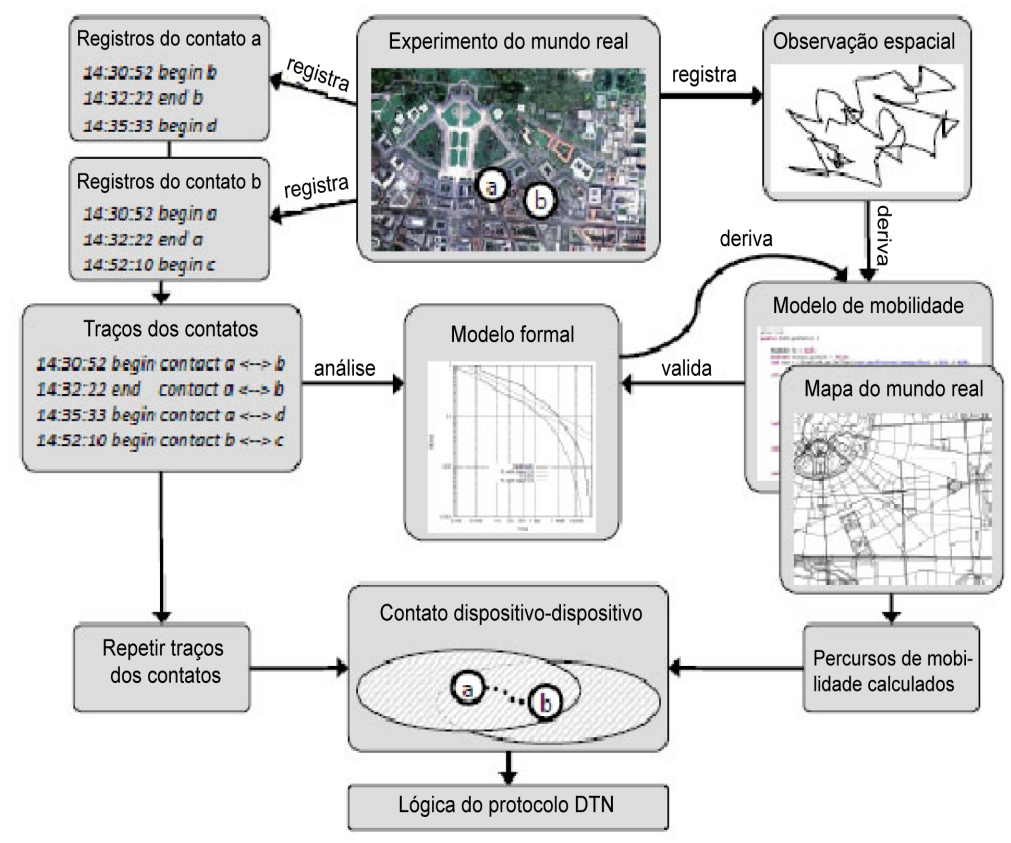

Figura 2.1: Componentes do simulador The One. Fonte: (Mayer, 2012).

Observamos na Figura 2.1 que o simulador The One apresenta diversas vantagens:

- Executa modelos de mobilidade e padrões de comunicação sem o auxílio de uma infraestrutura.

- Possibilita especificar a lógica do protocolo e o modelo de mobilidade para analisar e validar cenários.

- Sistematiza o processo de simulação e registra as informações dos contatos e dos intercontatos dos rastros simulados.

- Capacidade de visualização da execução dos cenários de comunicação e mobilidade das unidades móveis.

No desenvolvimento da pesquisa, propomos a arquitetura do arcabouço que usa o simulador The One para gerar os rastros de contatos DTNs e os seus componentes são elencadas a seguir:

- Cenário: é um ambiente de programação declarativo que possibilita definir as variáveis para a simulação dos modelos de mobilidade.

- Simulação/Codificação: nesta fase o simulador executa o modelo de mobilidade das unidades móveis do ecossistema DTNs definido no cenário e armazena as informações das oportunidades dos contatos nos rastros.

No cenário podemos configurar os parâmetros importantes para modelar ecossistemas DTNs relacionados com as unidades móveis (a semente, o modelo de mobilidade, a área 
geográfica, o raio de cobertura, quantidade de unidades móveis e o tempo de pausa). Um estudo prévio do simulador The One foi realizado com o objetivo de testar a sua sensibilidade em relação aos parâmetros elencados ( a semente, o modelo de mobilidade, a área geográfica, o raio de cobertura, a quantidade de unidades móveis e o tempo de pausa). Os resultados dos testes estão representados no Apêndice 1.

A função de mapeamento cria uma lista de agregados de subgrafos do grafo dinâmico (veja a definição na seção 2.3) de intervalo de tempo discreto e as métricas de redes complexas são aplicadas individualmente a cada snapshot gerando um conjunto de dados para desenvolver a análise estatística. A Figura 2.2 apresenta a arquitetura do arcabouço para aquisição de dados do grafo dinâmico.

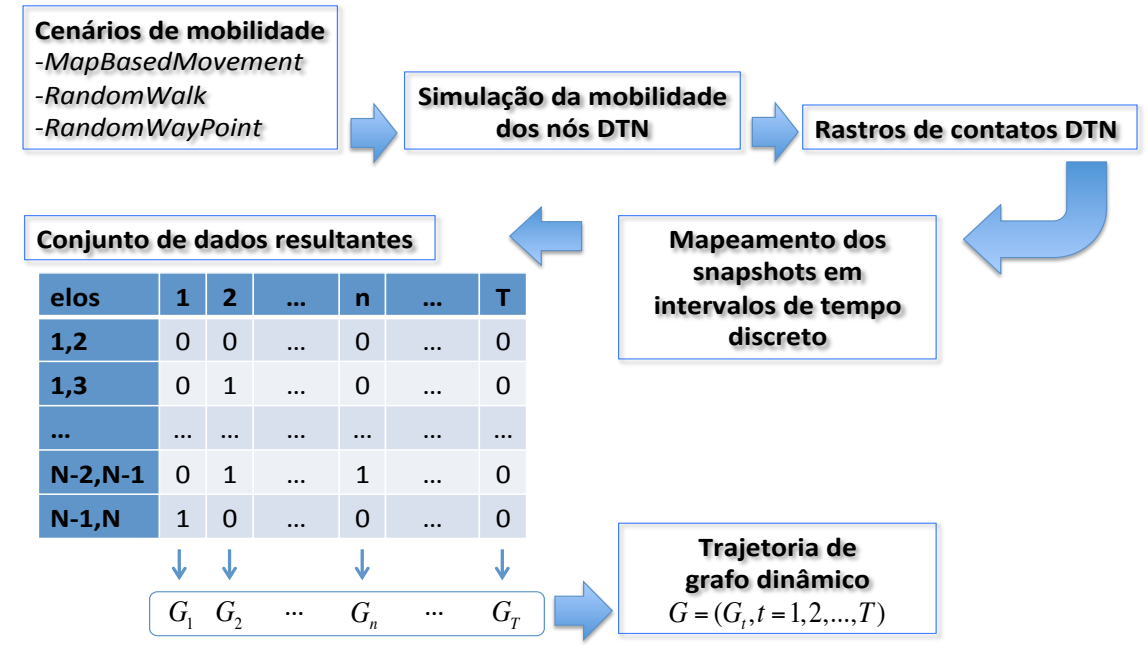

Figura 2.2: Arquitetura do arcabouço para aquisição de dados do grafo dinâmico.

Apresentamos as fases da arquitetura do arcabouço para aquisição de dados do grafo dinâmico:

- Usamos o conceito de cenário no simulador The One que possibilita descrever formalmente os parâmetros dos modelos de mobilidade (sementes, velocidade, tempo de parada, raio de comunicação, quantidade de nós).

- Executamos a compilação da simulação do cenário de mobilidade dos nós DTNs para registrar os encontros oportunistas entre as unidades móveis e armazenar nos rastros dos contatos DTNs os intervalos de tempo que ocorreram estes encontros.

- Implementamos o mapeamento dos rastros de contatos DTNs para o conjunto de snapshots do grafo dinâmico de intervalo de tempo discreto. Desta forma, o mecanismo do mapeamento possibilita a partir dos rastros de contatos criar a instância do grafo dinâmico de intervalo de tempo discreto.

- Aplicamos as métricas de redes complexas no conjunto de snapshots do grafo dinâmico de intervalo de tempo discreto com o objetivo de extrair informações estruturais da rede do ecossistema DTNs. 
- Desenvolvemos a análise estatística sobre o conjunto de dados resultantes das informações estruturais da rede do ecossistema DTNs relacionados com os modelos de mobilidade.

\subsection{Modelos de mobilidade no ecossistema das redes DTNs}

A mobilidade exerce forte influência na avaliação de desempenho das redes DTNs refletindo na intermitência das conexões, natureza dinâmica do meio, mudanças rápidas e imprevisíveis na sua estrutura [dSBHO15, CR13, KAF12, FF08]. Os modelos de mobilidade são relevantes para fornecer informações sobre o padrão de conectividade da estrutura da topologia auxiliando as atividades da análise comparativa dos rastros de contatos das redes DTNs [CBD02, KKO10, San12]. Neste contexto, os modelos de mobilidade devem ser suficientemente simples para ser integrado nas atividades de simulação e facilitar a obtenção de conjuntos de dados para desenvolver a análise estatística dos rastros de contatos no ecossistema das redes DTNs na presença da mobilidade.

Apresentamos o princípio de funcionamento de três modelos de mobilidade frequentemente utilizados no ecossistema das redes DTNs [CBD02, WGG10].

- Map Based Movement: este modelo de mobilidade é útil para modelar situações realistas em que as unidades móveis devem mover-se dentro de caminhos específicos no ecossistema das redes DTNs. O uso de modelos baseado em mapas envolve a fase de configuração dos caminhos do mapa e usar cenários para definir as regras de mobilidade dos nós DTNs. A velocidade da unidade móvel é escolhida uniformemente no intervalo $\left[v_{\min }, V_{\max }\right]$, tal que $v_{\min }$ e $V_{\max }$ são as velocidades mínima e máxima da unidade móvel no ecossistema DTN. Quando a unidade móvel chega ao destino, ela permanece parada por um tempo de pausa pré-definido, e, em seguida, começa a se mover novamente de acordo com o mesmo padrão.

- Random Walk: no modelo de mobilidade random walk, a velocidade do vetor $\vec{v}=$ $(v, \theta)$ das unidades móveis no ecossistema DTN é determinada pelo valor absoluto da velocidade $v$ e pelo ângulo $\theta$. Ela muda a todo momento que a unidade móvel se move no tempo t ou distância d. Quando a velocidade muda, a velocidade e a direção são arbitrariamente selecionadas entre as velocidades mínima e máxima pré-definidas $\left[v_{\min }, V_{\max }\right]$ e $[0,2 \pi)$. Quando a unidade móvel chega na fronteira da área de simulação, ela é lançada de volta para a área de simulação com ângulo de $\theta(t)$ ou $\pi-\theta(t)$, este efeito é chamado de efeito de borda. O modelo de mobilidade random walk é um processo de mobilidade sem memória, ou seja, a mudança na velocidade e direção não tem nenhuma dependência com as mudanças anteriores e com outras unidades móveis DTNs. 
- Random Waypoint: o modelo de mobilidade random waypoint, introduz o conceito de tempo de pausa $\tau$ durante o movimento em que cada unidade móvel no ecossistema DTN escolhe uniformemente e aleatoriamente um ponto de destino dentro da região de implantação $R$, e se move em direção a ela ao longo de uma linha reta. A velocidade da unidade móvel é escolhida uniformemente e aleatoriamente no intervalo $\left[v_{\min }, V_{\max }\right]$. Quando a unidade móvel chega ao destino, ela permanece parada por um tempo de pausa pré-definido, e, em seguida, começa a se mover novamente de acordo com o mesmo padrão.

\subsection{Grafos Dinâmicos}

A compreensão do fenômeno físico do conceito de grafo dinâmico de intervalo de tempo discreto relacionado com os rastros de contatos das redes DTNs introduzem uma linguagem cuja notação é formalizada matematicamente, e por isso possui significado preciso [CFQS12, $\left.\mathrm{SQF}^{+} 11\right]$. Esta notação está associada diretamente com a evolução temporal dos snapshots de um grafo dinâmico de tempo discreto que possibilita aplicar métricas de redes complexas para extrair propriedades da conectividade relacionadas com a dinâmica da sua topologia.

No contexto da pesquisa, o método científico que utilizamos é a técnica de simulação para compreender o conceito de grafo dinâmico de intervalo de tempo discreto relacionado com a conectividade existente nos rastros de contato das redes DTNs. A observação do fenômeno físico parte do pressuposto de que para compreender esta ciência, é importante dominar a linguagem utilizada por ela.

Casteigts et al. [CKNP15] nos dá a seguinte definição.

Definição (Grafo Dinâmico) Um grafo dinâmico de intervalo de tempo discreto é formado por uma sequência $G=\left\{G_{1}, G_{2}, \ldots, G_{T}\right\}$ de grafos $G_{t}=\left(V, E_{t}\right)$, chamados snapshots, que descrevem a topologia da rede de contatos em intervalos de tempos $t$, para $t=1,2, \ldots, T$.

O parâmetro $T$ no modelo é denominado de comprimento da sequência $G$ e corresponde ao número de intervalos de tempo discreto do grafo dinâmico. Note que, para todo $G_{t}$, o conjunto $V$ é o mesmo, somente o conjunto de arestas é variável. A Figura 2.3 apresenta um exemplo de grafo dinâmico de intervalo de tempo discreto associado com um cenário de mobilidade de um rastro DTNs.

Apresentamos a seguir a definição formal de rastro de contato no contexto do ecossistema das redes DTNs. 


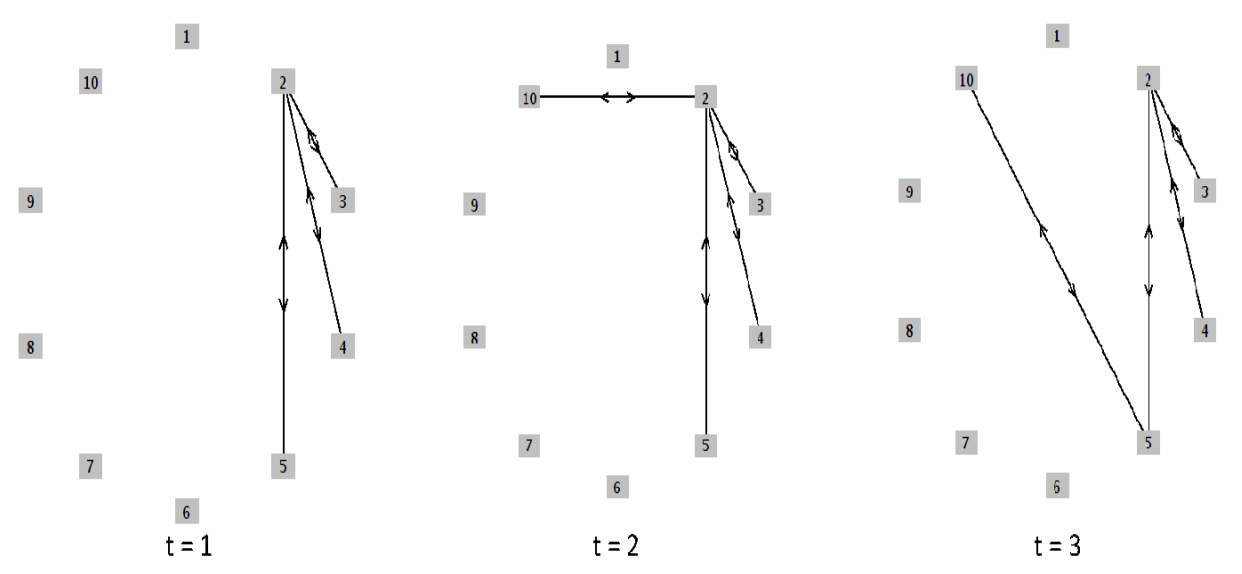

Figura 2.3: Exemplo de grafo dinâmico de intervalo de tempo discreto associado com um cenário de mobilidade de um rastro de contatos DTNs.

Definição (Rastro de Contato) Um contato entre dois nós $i, j \in \mathbb{N}$ é representado por uma quádrupla $c=\left(i, j, t, \delta_{t}\right)$, em que $0 \leq t \leq T$ é o tempo em que o contato é iniciado e $\delta_{t}$ é a sua duração, expressa em unidades temporais [HS13]. A relação entre $i$ e $j$ é geralmente não persistente, de modo que, observamos mais de um contato entre $i$ e $j$ no intervalo $[0, T]$.

A dinâmica relacionada com os contatos ou intercontatos no grafo dinâmico pode ser visto como um processo aleatório (ou estocástico). Desta forma, a sequência de variáveis aleatórias que representam o tempo de contato e intercontato é um componente relevante relacionado com o comportamento da mobilidade desempenhado pelas unidades móveis na topologia da rede de ecossistemas DTNs.

Esta visão da teoria da probabilidade é relevante devido aos métodos e técnicas sofisticadas que podem ser aplicadas em cenários de pesquisas desafiadoras de mobilidade de ecossistemas DTNs. 


\section{Capítulo 3}

\section{Distribuição dos tempos de contato e intercontato}

No Capítulo 1, definimos três componentes principais na construção do grafo dinâmico. Os dois primeiros componentes são as distribuições dos tempos de intercontatos (componente (i) ) e contatos (componente (ii)). Neste Capítulo sempre assumiremos que a distribuição de ambos os tempos não depende dos pares de unidades móveis. Assim, $F_{i j} \equiv F$ e $G_{i j} \equiv G$.

\subsection{Tempo de intercontato}

O tempo de intercontato é uma das principais métricas de avaliação de desempenho de comunicações oportunistas. Desta forma, fornecemos alguns argumentos experimentais e teóricos sobre a distribuição da cauda exponencial para o tempo de intercontato nos modelos de mobilidade MapBasedMovement, Random Walk e Random Waypoint considerados.

Começamos com as seguintes definições. A função de distribuição cumulativa $F(x)$ proporciona descrever como as probabilidades são associadas com a sequência de valores de uma variável aleatória. De forma geral, considere o espaço de probabilidade $(\Omega, \mathcal{F}, \mathbb{P})$.

Definição (Função de distribuição cumulativa de uma variável aleatória $X$ ) é uma função que a cada número real $x$ associa o valor.

$$
F(x)=\mathbb{P}(X \leq x), \quad x \in \mathbb{R} .
$$


Definição (Função de distribuição cumulativa complementar (Complementary Cumulative Distribution Function, $C C D F$ ) de uma variável aleatória $X$ ) é uma função que a cada número real $x$ associa o valor.

$$
F^{c}(x)=1-F(x), \quad x \in \mathbb{R}
$$

A notação $\{X \leq x\}$ é usada para designar o conjunto $\{\omega \in \Omega: X(\omega) \leq x\} \subset \mathcal{F}$, isto é, denota a imagem inversa do intervalo $(-\infty, x]$ pela variável aleatória $X$. Com isso, podemos observar que a função de distribuição acumulada $F$ tem como domínio os números reais $\mathbb{R}$ e imagem o intervalo $[0,1]$.

O conhecimento da função de distribuição acumulada é suficiente para entendermos o comportamento de uma variável aleatória. Mesmo que a variável assuma valores apenas em um subconjunto dos reais, a função de distribuição é definida em toda a reta. Ela é chamada de função de distribuição acumulada, pois acumula as probabilidades dos valores inferiores ou iguais a $x$.

O trabalho mais relevante nesta área de pesquisa de acordo com Karagiannis, Le Boudec e Vojnovic [KBV10], foi desenvolvida por Chaintreau et al. [ $\left.\mathrm{CHC}^{+} 07\right]$ que foram talvez os primeiros a relatar evidências empíricas concretas sugerindo que a função de distribuição cumulativa complementar (CCDF) do tempo de intercontatos entre dispositivos móveis transportado por humanos segue uma lei de potência em uma ampla faixa de valores que abrangem as escalas de tempo de alguns minutos até metade do dia. Esta constatação empírica motivou Chaintreau et al. $\left[\mathrm{CHC}^{+} 07\right]$ a formular a hipótese de que o tempo de intercontatos tem uma CCDF com cauda de lei de potência.

Acreditamos que a suposição sobre a cauda da distribuição com cauda de lei de potência seja muito pessimista, porque teoricamente o fato de que a cauda deve ser exponencial segue diretamente do fato de que todos os modelos de mobilidade considerados são executados em uma grande área $A$, mas finita. Embora o comportamento da lei de potência seja também observado em nossas simulações, mas isso deve ocorrer até um intervalo finito de tempo, e além do qual a distribuição decai exponencialmente. Esse fenômeno foi denominado de dicotomia por [KBV10]. Nesta perspectiva, também propomos alguns modelos de distribuições para o tempo de contato.

Para avaliar (estimar) a CCDF com base nas observações dos tempos de intercontatos $x_{1}, x_{2}, \ldots, x_{n}$ usaremos a seguinte fórmula da distribuição cumulativa empírica e a complementar dela:

$$
\hat{F}(x)=\frac{1}{n} \sum_{i=1}^{n} \mathbf{1}\left(x_{i} \leq x\right), \quad \widehat{F}^{c}(x)=\frac{1}{n} \sum_{i=1}^{n} \mathbf{1}\left(x_{i}>x\right)
$$

em que 1(·) é indicador de evento correspondente: 


$$
\mathbf{1}\left(x_{i} \leq x\right)=\left\{\begin{array}{l}
1, \text { se } x_{i} \leq x \\
0, \text { se } x_{i}>x
\end{array} \quad \mathbf{1}\left(x_{i}>x\right)=1-\mathbf{1}\left(x_{i} \leq x\right) .\right.
$$

Consideramos dois cenários de decaimento das caudas: polinomial (lei de potência) e exponencial. O decaimento polinomial caracteriza-se pela seguinte relação

$$
F^{c}(x) \sim \operatorname{const} \cdot x^{-\gamma}
$$

para um parâmetro $\gamma>0$ fixo, quando $x$ é suficientemente grande, tal que $\sim$ significa

$$
\lim _{x \rightarrow \infty} \frac{F^{c}(x)}{x^{-\gamma}}=\text { const }
$$

Decaimento exponencial por sua vez está definido como

$$
F^{c}(x) \sim \text { const } \cdot e^{-\gamma x},
$$

quando $x$ suficientemente grande e $\gamma>0$, tal que $\sim$, como anteriormente significa

$$
\lim _{x \rightarrow \infty} F^{c}(x) e^{\gamma x}=\text { const }
$$

A transformada logarítmica de (3.1.1,3.1.2) representa essas relações na forma alternativa: para lei de potência

$$
\ln \left(F^{c}(x)\right) \sim \text { const }-\gamma \ln (x),
$$

e para decaimento exponencial

$$
\ln \left(F^{c}(x)\right) \sim \text { const }-\gamma x
$$

Assim, caso as observações vão seguir a lei de potência, então nos eixos

$$
\ln (x), \ln \left(\widehat{F}^{c}(x)\right)
$$

podemos observar uma reta (aproximadamente). Caso as observações vão seguir a lei exponencial, então nos eixos

$$
x, \ln \left(\widehat{F}^{c}(x)\right)
$$

podemos observar aproximadamente uma reta.

Os resultados da simulação da CCDF empírica do tempo de intercontatos para os três cenários considerados estão representados na Figura 3.1. Para a trajetória do grafo dinâmico de cada modelo de mobilidade foram extraídos os tempos observados de intercontatos $x_{1}, x_{2}, \ldots, x_{n}$ para todos os pares de unidades móveis. Assumindo que a distribuição não dependem dos pares de unidades móveis $F_{i j} \equiv F$, calculamos para cada $x$ o valor de $\hat{F}^{c}(x)$ e plotamos. 
A simulação mostra que no modelo Random Walk a cauda apresenta lei de potência. No modelo Random Waypoint a cauda é exponencial. O modelo MapBasedMovement apresenta tendência a mostrar o fenômeno da dicotomia, introduzida por [KBV10]. Desta forma, a dicotomia é definida como: a CCDF do tempo de intercontato segue de perto decaimento de lei de potência até um tempo característico, e após esse tempo a CCDF segue decaimento exponencial.

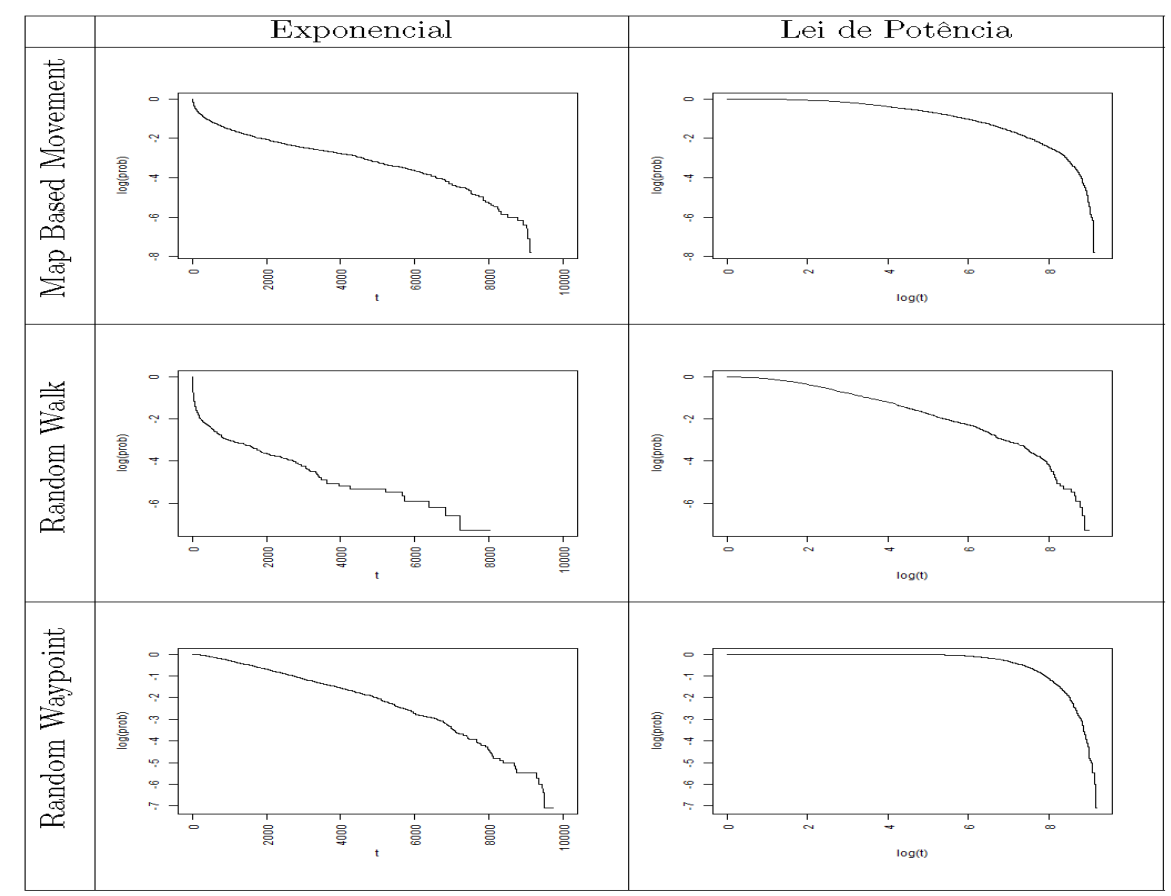

Figura 3.1: Resultados dos cenários de intercontatos dos modelos de mobilidade (MapBasedMovement, RandomWalk e Random Waypoint).

Todos os cenários de simulação foram naturalmente executados em uma área finita (4500 m x $3400 \mathrm{~m}$ ), e pode ser representada teoricamente como um cadeia de Markov de tempo discreto. Significa por resultados teóricos que o tempo de intercontato que a CCDF deveria ter cauda exponencial.

\subsubsection{Tempo de intercontato mobilidade Random WayPoint.}

Relembramos como funciona o modelo Random WayPoint. Supomos que a unidade móvel está no ponto $x_{0} \in A$. A unidade móvel escolhe aleatoriamente e uniformemente um ponto $x_{1} \in A$ e vai até esse ponto com velocidade $v$ fixa para este modelo de mobilidade. Existe uma opção de que a velocidade seja escolhida ao acaso (segundo uma distribuição).

Assim, formalmente podemos representar o processo Random WayPoint como cadeia de Markov. Para descrevê-la supomos no momento que existe somente uma unidade móvel. O estado contém dois parâmetros: a posição corrente da unidade e o ponto para onde ela está indo. Assim, antes de atingir o ponto-alvo a unidade móvel escolhe a próxima 
posição deterministicamente (com probabilidade 1). Chegando ao ponto-alvo escolhe aleatoriamente o novo ponto-alvo.

Para mostrar o resultado matemático sobre a distribuição do tempo de intercontato para Random WayPoint usaremos uma versão simplificada dessa mobilidade. Reduzimos o conjunto dos estados para o conjunto de estados-alvo. A velocidade resultante desta redução não é mais constante e é uma função do próximo estado alvo e do alvo anterior.

Consideramos a seguinte cadeia de Markov $X_{n}$, com tempo discreto, $n=0,1, \ldots$ e com estados dentro de uma área $A, X_{n} \in A$ : em cada instante escolhemos o estado uniformemente em $A$ e independentemente do estado anterior. Esta cadeia chamaremos Random WayPoint simplificada.

Sejam $x_{1}, x_{2} \in A$ dois pontos distintos quaisquer. Definimos $R\left(x_{1}, x_{2}\right)$ o rastro do círculo com raio $r$ :

$$
R\left(x_{1}, x_{2}\right)=\left\{x \in A \text { : distância entre } x \text { e o intervalo }\left[x_{1}, x_{2}\right] \text { é menor ou igual a } r\right\} .
$$

Seja $X_{n}, Y_{n}$ duas cadeias Random WayPoint simplificadas independentes descritas acima. Falaremos que as duas cadeias tiveram o contato durante o tempo $[n, n+1)$ se os rastros $R\left(X_{n}, X_{n+1}\right)$ e $R\left(Y_{n}, Y_{n+1}\right)$ dos dois círculos com raio $r$ com centros passando pelos intervalos $\left[X_{n}, X_{n+1}\right]$ e $\left[Y_{n}, Y_{n+1}\right]$ se-intersectam, $R\left(X_{n}, X_{n+1}\right) \cap R\left(Y_{n}, Y_{n+1}\right) \neq \emptyset$. Seja $T$ um tempo de contato:

$$
T=\min \left\{n: X_{n}, Y_{n} \text { tiveram um contato durante }[n-1, n)\right\}
$$

Lema 3.1.1 Existe $\varepsilon>0$ tal que o tempo de contato no modelo de mobilidade RandomWayPoint simplificado descrito acima

$$
\mathbb{P}(T>n)<(1-\varepsilon)^{n},
$$

uniformemente pelos estados iniciais $X_{0}, Y_{0} \in A$.

Prova. É fácil ver que $\varepsilon$ pode ser escolhido como a probabilidade de que a distância entre os dois pontos escolhidos aleatoriamente e uniformemente no conjunto $A$ seja menor ou igual a $2 r$ :

$$
\varepsilon=\frac{1}{\mathrm{~A}} \iint_{A \times A} \mathbf{1}(\mathrm{x}-\mathrm{y} \leq 2 r) d x d y
$$

de forma que A seja a área do conjunto $A$ e $\mathbf{1}(\cdot)$ seja a função indicadora. Assim, para qualquer $n$ a probabilidade

$$
\mathbb{P}\left(R\left(X_{n-1}, X_{n}\right) \cap R\left(Y_{n-1}, Y_{n}\right) \neq \emptyset\right)>\varepsilon
$$

uniformemente pelas posições $X_{n-1}, Y_{n-1}$, tal que prova o lema.

É evidente que o Lema 3.1.1 não prova diretamente que a distribuição do tempo de 
intercontato para a mobilidade RandomWayPoint original é exponencial, mas ela dá uma ideia de porque isso é verdade. Realmente, sejam $X_{n}, Y_{n}$ dois processos Random WayPoint. Supomos que no instante $n X_{n}$ parou e está escolhendo a próxima direção (lembramos que a velocidade é constante). Então existe $\varepsilon>0$ tal que a probabilidade de que o próximo ponto para onde vai $X$ vai ser escolhido tal que, durante o novo trajeto $X$ e $Y$ vão ter o contato, essa probabilidade é maior que $\varepsilon$ independentemente das posições correntes de $X$ e de $Y$.

As simulações do The One confirmam explicitamente que o tempo de intercontato na mobilidade Random WayPoint tem caráter exponencial, veja a Figura 3.1.

\subsubsection{Tempo de intercontato mobilidade Random Walk.}

Os modelos de mobilidade do tipo Random Walk podem ser representados pelos modelos de passeios aleatórios muito populares na probabilidade. Existem vários resultados conhecidos sobre passeios aleatórios que podem ser úteis na análise do tempo de intercontato para a mobilidade RandomWalk.

Relembramos como o Random Walk funciona no simulador The One. Seja a velocidade $v$ dessa mobilidade fixa. A unidade móvel que está em um ponto $x_{0} \in A$ é escolhida aleatoriamente e uniformemente uma direção $\alpha_{0}, \alpha_{0} \sim U[0,2 \pi)\left(\alpha_{0}\right.$ possui distribuição uniforme no intervalo $[0,2 \pi)$ ) e segue de acordo com a direção escolhida durante o tempo (tempo discreto) $t_{0}$ com velocidade $v$ chegando no ponto $x_{1}$. O tempo $t_{0}$ tem a distribuição geométrica com parâmetro $p: \mathbb{P}\left(t_{0}=k\right)=(1-p)^{k-1} p$, ou seja $t_{0} \sim G(p)$. No ponto $x_{1}$ o procedimento se repete: a unidade escolhe independentemente uma direção $\alpha_{1} \sim U[0,2 \pi)$ e o tempo $t_{1} \sim G(p)$ e segue na direção $\alpha_{1}$ durante o tempo $t_{1}$ chegando no ponto $x_{2}$.

Assim, a trajetória é determinada pela sequência de direções $\alpha_{i}$ que são independentes e identicamente distribuídas (i.i.d.) com a distribuição uniforme em $[0,2 \pi)$ e com a sequência dos tempos de trajetos retos $t_{i}$ que são i.i.d. com a distribuição geométrica $G(p)$. Caso a trajetória encontre a borda da área $A$, a trajetória reflete-se pela lei de reflexão (ângulo de decaimento igual ao ângulo de reflexão).

Denotamos $X_{n}^{R W}$ a posição da unidade móvel no instante $n$. Sejam $\tau_{i}$ instantes quando a unidade móvel escolhe uma direção $\alpha_{i+1}$ e tempo $t_{i+1}$,

$$
\tau_{i}=t_{0}+\cdots+t_{i}, \quad i=0,1, \ldots
$$

Consideramos o processo $X_{n}$ embutido nestes instantes: $X_{n}=X_{\tau_{n}}^{R W} \cdot X_{n}$ é cadeia de Markov conhecida como passeio aleatório em $A$ com incrementos definidos pelo par $\left(\alpha_{n}, t_{n}\right)$, supondo que $v \equiv 1$. Observe que o passeio $X_{n}$ em $\mathbb{R}^{2}$ tem incremento médio igual a zero

$$
E\left(X_{n}-X_{n-1} \mid X_{n-1}\right)=0
$$


o que faz $X_{n}$ ser um martingale

$$
E\left(X_{n} \mid X_{n-1}\right)=X_{n-1} \text {, quase certamente. }
$$

O passeio aleatório usualmente estudado em probabilidade é o passeio aleatório em reticulado. Para relacionar os resultados sobre os passeios aleatórios em reticulado com mobilidade Random Walk faremos discretização do espaço $A$, consideramos espaço discreto $A_{d}=\mathbb{Z}^{2} \cap A$ em vez de $A$. Para cada $s \in A_{d}$ associamos o quadrado $q_{s} \subset A$ cujos pontos estão mais próximos do ponto $s$ que os outros pontos do reticulado $A_{d}$. A densidade de transição será transformada em probabilidade de transição: seja $\tilde{X}_{n}$ um passeio aleatório discreto no reticulado $A_{d}$ induzido por $X_{n}$, então para quaisquer $j, j^{\prime} \in A_{d}$

$$
P\left(\tilde{X}_{n}=j^{\prime}, \tilde{X}_{n-1}=j\right)=\iiint \mathbf{1}\left(r \in q_{j}, r+(\alpha, t) \in q_{j^{\prime}}\right) d r d \mu(\alpha) d \nu(t),
$$

tal que a medida $d \mu$ é uniforme em $[0,2 \pi)$, a medida $d \nu$ é exponencial, e $d r$ a medida de Lebesgue em $\mathbb{R}^{2}$. O processo $\tilde{X}_{n}$ no reticulado $A_{d}$ com probabilidades de transição (3.1.6) forma uma cadeia de Markov. O seguinte lema é básico para cadeias de Markov com tempo discreto e com número de estados finito (veja por exemplo [Fel68]).

Lema 3.1.2 Seja $\tilde{X}_{0}=x \in A_{d} e$

$$
\tilde{T}_{x}=\min \left\{n: \tilde{X}_{n}=x\right\}
$$

Passeio aleatório $\tilde{X}_{n}$ em $A_{d}$ é cadeia de Markov ergódica e existem constantes positivas $c, \gamma$ tais que

$$
P\left(\tilde{T}_{x} \geq n \mid \tilde{X}_{0}=x\right)<c e^{-\gamma n} .
$$

Novamente como no caso da mobilidade Random Waypoint, esse lema não prova diretamente que o tempo de intercontato para a mobilidade RandomWalk possui cauda exponencial, mas dá ideia de que isso é verdade. Realmente, seja $X_{n}^{R W}, Y_{n}^{R W}$ dois processos de mobilidade RandomWalk descrito acima. Seja $T_{x, y}^{R W}$ o tempo do primeiro contato para dois processos, lembrando que o contato ocorre no instante $n$, se a distância entre os processos no instante $n$ for menor ou igual a $2 r$,

$$
T_{x, y}^{R W}=\min \left\{n:\left\|X_{n}^{R W}-Y_{n}^{R W}\right\| \leq 2 r\right\}
$$

tal que $x, y \in A$ sejam estados iniciais, $X_{0}^{R W}=x, Y_{0}^{R W}=y$. Consideramos também o tempo de contato para os passeios aleatórios $\tilde{X}_{n}, \tilde{Y}_{n}$ :

$$
\tilde{T}_{x, y}=\min \left\{n:\left\|\tilde{X}_{n}-\tilde{Y}_{n}\right\| \leq 2 r\right\},
$$

tal que $x, y \in A_{d}$ sejam estados iniciais, $\tilde{X}_{0}=x, \tilde{Y}_{0}=y$. Assim, a seguinte relação é 
válida: quase certamente

$$
T_{x, y}^{R W} \leq \sum_{i=0}^{\tilde{T}_{x, y}} t_{i} \equiv \tau_{\tilde{T}_{x, y}} .
$$

Realmente, no instante $\tau_{\tilde{T}_{x, y}}$ ocorre o contato, mas o contato poderia acontecer também durante os trajetos $t_{i}$ o que não está sendo controlado. Existem constantes positivas $c, \gamma$ tais que

$$
P\left(T_{x, y}^{R W} \geq n \mid X_{0}^{R W}=x, Y_{0}^{R W}=y\right)<c e^{-\gamma n} .
$$

A prova vem diretamente do fato de que as variáveis $t_{i}$ tem distribuição geométrica e o número de membros da soma em (3.1.7) possuem cauda exponencial.

Notamos que o tempo de intercontato é o tempo de retorno para o processo, que é igual a diferença entre os dois processos. A diferença dos dois processos $Z_{n}=X_{n}^{R W}-Y_{n}^{R W}$ também é um processo da mesma mobilidade, que pode ser com outros parâmetros. Assim o tempo de intercontato entre $X_{n}^{R W}$ e $Y_{n}^{R W}$ é o tempo de retorno para o processo $Z_{n}$.

Sabe-se que o tempo de retorno de um passeio aleatório simétrico (quando a média do incremento é igual a zero) em $\mathbb{Z}^{2}$ tem cauda polinomial. Então é possível em uma extensa área $A$ em comparação com a área de contato não observar empiricamente a cauda exponencial. O que acontece nas simulações da mobilidade Random Walk no The One, veja a Figura 3.1.

Teoricamente, o comportamento do tempo de contato na mobilidade Random Walk e a cadeia de Markov bem conhecida de passeio aleatório simples (simple random walk) em reticulado de um torus unidimensional (tal que as probabilidades de pulos para frente e para trás tem probabilidades $1 / 2$ ) e bidimensional (com probabilidades de pulos em 4 direções iguais a 1/4) devem ser parecidas. Por isso, realizamos simulações para observar empiricamente o tempo de retorno. Embora formalmente, o tempo de retorno de um passeio aleatório simples seja diferente do tempo de encontro de dois passeios aleatórios simples, mas as distribuições deles possuem formas parecidas.

As simulações mostram perfeitamente o decaimento da cauda exponencial na simulação do tempo de intercontato para o random walk simples nos torus unidimensional e bidimensional, ver a Figura 3.2 para o caso unidimensional e a Figura 3.3 para o torus bidimensional. E também podemos observar que antes de algum tempo a forma da distribuição complementar é polinomial. Esse fenômeno foi denominado de dicotomia por [KBV10]. 


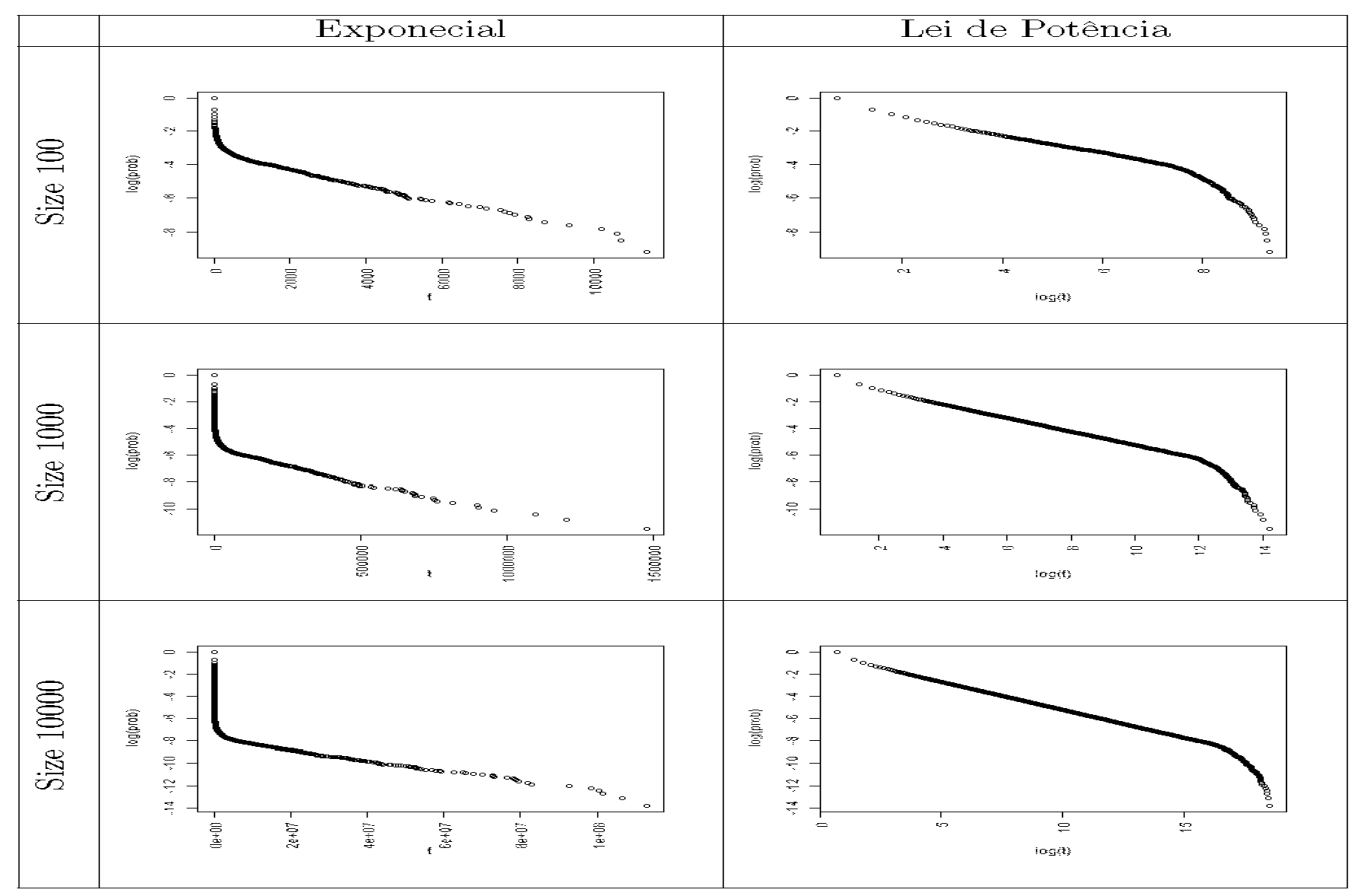

Figura 3.2: Resultados dos cenários de simulação do modelo random walk no torus unidimensional para diferentes tamanhos do torus: 100,1000 e $10^{4}$.

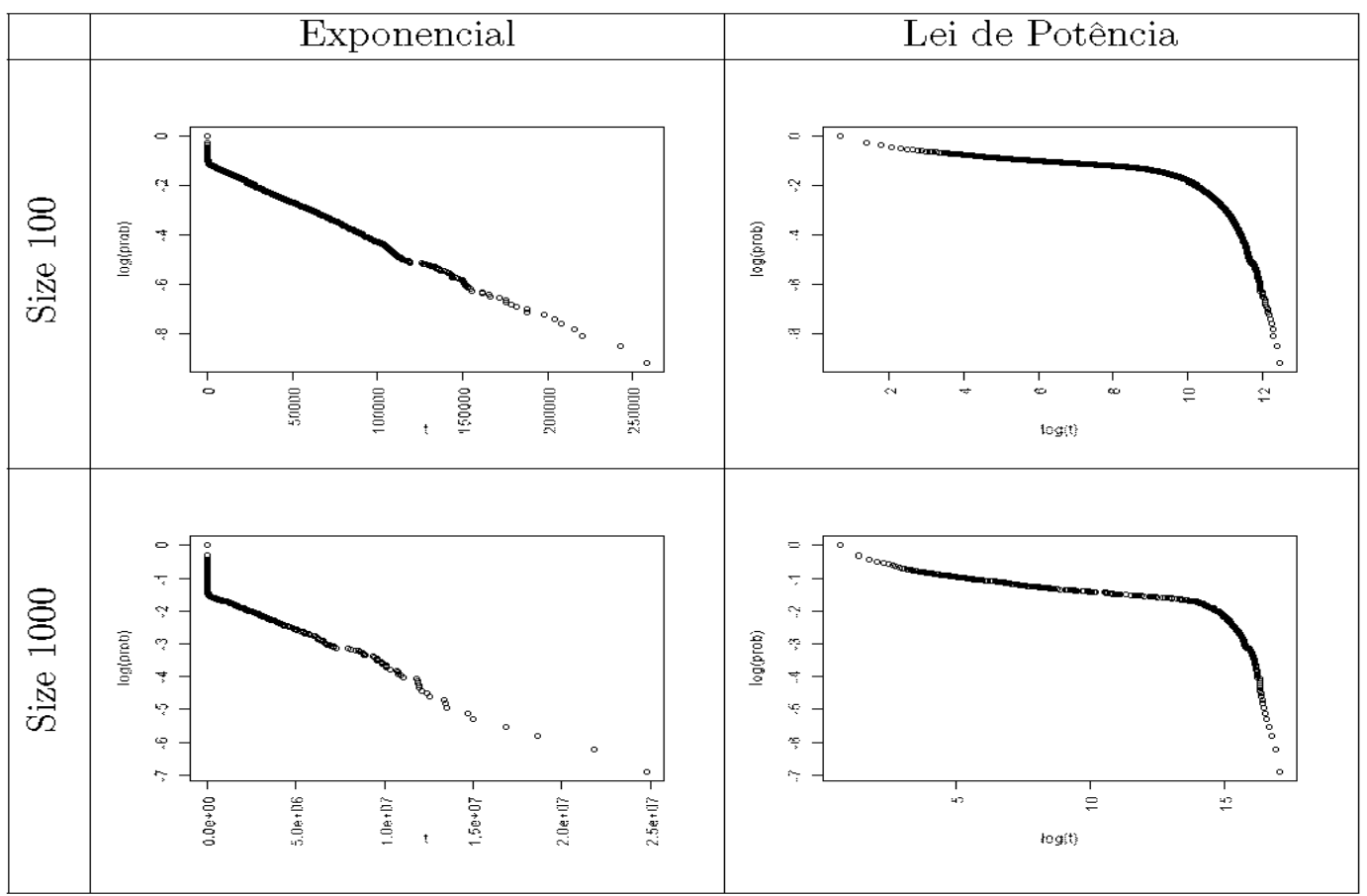

Figura 3.3: Resultados dos cenários de simulação do modelo random walk no torus bidimensional para diferentes tamanhos do torus: $100 \times 100,1000 \times 1000$. 


\subsubsection{Tempo de intercontato MapBasedMovement.}

Entre os três tipos de mobilidade, a mobilidade MapBasedMovement é a mais próxima da realidade. A mobilidade Random Walk e MapBasedMovement podem ser definidas em um volume infinito, em $\mathbb{R}^{2}$, espalhado em um mapa infinito. Assim, MapBasedMovement pode ser visto como um passeio aleatório em um grafo planar embutido em $\mathbb{R}^{2}$ com a diferença de que os movimentos dentro dos elos são determinísticos, os saltos do passeio ocorrem com probabilidade 1 em uma direção escolhida, da mesma forma como ocorre no modelo de mobilidade Random WayPoint: os estados da cadeia são compostos não somente da posição das unidades móveis, mas também de um próximo ponto de bifurcação (próximo cruzamento) de forma que a unidade móvel escolhe a sua próxima direção, ou próximo ponto de cruzamento aleatoriamente e uniformemente.

Desse ponto de vista MapBasedMovement é representado como uma cadeia de Markov com o conjunto de estados mais complexo que $\mathbb{R}^{2 N}$ mas ainda é finito. Assim, teoricamente, MapBasedMovement tem que apresentar a cauda exponencial. O que é confirmado empiricamente pelas simulações, veja na Figura 3.1.

\subsection{Tempo de Contato}

Embora o conceito do tempo de contato seja natural e as contas não sejam difíceis, tradicionalmente a literatura não menciona a distribuição do tempo de contato. Isso acontece provavelmente porque a duração do tempo de contato em geral é muito menor do que a duração do tempo de intercontato das redes DTNs.

\subsubsection{Modelo matemático da distribuição do tempo de contato.}

O tempo de duração do contato é o tempo de intersecção de dois círculos de raio $r$ que se movimentam com uma velocidade $v_{o}$ fixa. A distribuição desse tempo é difícil de achar analiticamente, por isso resolvemos achar a distribuição desse tempo baseando-se em simulações. O tempo da interseç̧ão depende dos parâmetros $r, v_{0}$ e também depende do ângulo sob o qual os dois círculos vão se interseccionar. Veja a Figura 3.4.

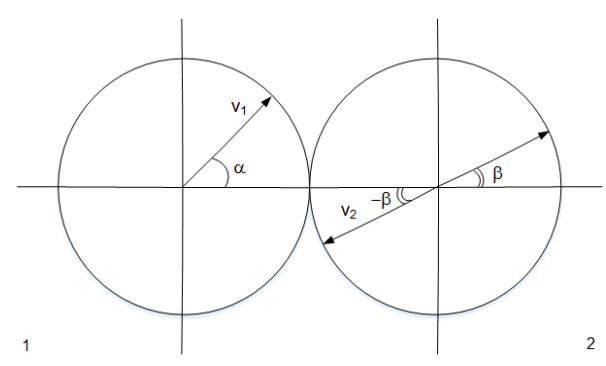

Figura 3.4: Modelo de percurso livre de duas unidades móveis.

Se $\alpha, \beta \in\left(\frac{-\pi}{2}, \frac{\pi}{2}\right)$, então as direções $\alpha$ (denotamos como vetor unitário $\vec{v}_{1},\left\|\vec{v}_{1}\right\|=1$ ) e oposta para $\beta$ (denotamos como vetor unitário $\bar{v}_{2},\left\|\vec{v}_{2}\right\|=1$ ) com certeza se intersectam. 
Consideramos o vetor $\vec{v}_{1}-\vec{v}_{2}$. Isso significa que o círculo 2 vai ser estático, enquanto o círculo 1 vai se movimentar com velocidade $\vec{v}_{1}-\vec{v}_{2}$ e com ângulo $\alpha+\beta \in\left(-\frac{\pi}{2}, \frac{\pi}{2}\right)$, e o círculo 1 com certeza vai intersectar o círculo 2.

Veja agora a Figura 3.5. Se o círculo 1 movimenta-se pelo ângulo $\varphi \in\left(\frac{-\pi}{2}, \frac{\pi}{2}\right)$, então a distância que passa o centro do círculo 1 durante a intersecção é a distância $d(\varphi) \equiv$ $O B=4 r \cos \varphi$.

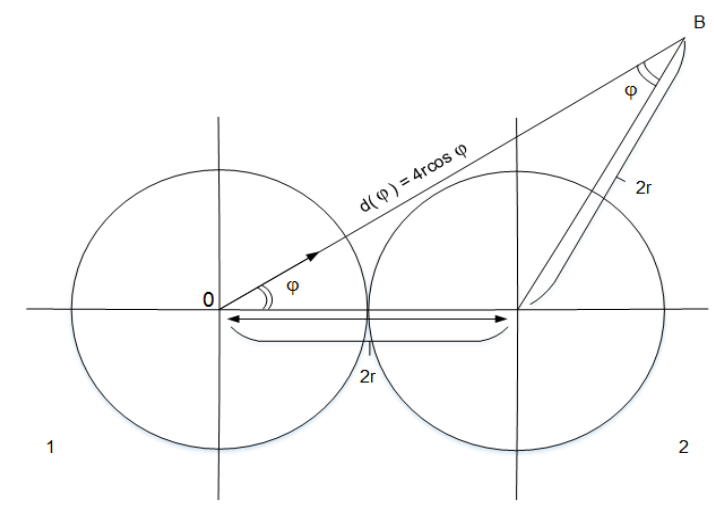

Figura 3.5: Modelo de percurso livre de duas unidades móveis.

Se $\alpha, \beta \in\left(\frac{-\pi}{2}, \frac{\pi}{2}\right)$ então o vetor de velocidade $\vec{v}_{1}-\vec{v}_{2}$ vai ter o ângulo $\varphi=\frac{\alpha+\beta}{2}$ e o valor absoluto desse vetor velocidade é

$$
\begin{aligned}
& \left\|\vec{v}_{1}-\vec{v}_{2}\right\|^{2}=(\cos \alpha+\cos \beta)^{2}+(\sin \alpha+\sin \beta)^{2}=2(1+\cos (\alpha-\beta)), \\
& \left\|\vec{v}_{1}-\vec{v}_{2}\right\|=\sqrt{2(1+\cos (\alpha-\beta))} .
\end{aligned}
$$

Lembrando que os círculos se movimentam com velocidade $v_{0}$, assim o valor absoluto da velocidade de intersecção é $v_{\alpha, \beta}=v_{0}\left\|\vec{v}_{1}-\vec{v}_{2}\right\|$ que dá o valor

$$
v_{\alpha, \beta}=v_{0} \sqrt{2(1+\cos (\alpha-\beta))} .
$$

E o tempo de duração dessa intersecção

$$
t_{\alpha, \beta}=\frac{d \varphi}{v_{\alpha, \beta}}=\frac{4 r \cos \left(\frac{\alpha+\beta}{2}\right)}{v_{0} \sqrt{2} \sqrt{1+\cos (\alpha-\beta)}} .
$$

$t_{\alpha, \beta}$ é variável aleatória (provavelmente com cauda pesada). Não é difícil ver que vale a seguinte forma alternativa de (3.2.1)

$$
t_{\alpha, \beta}=\frac{4 r}{v_{0} \sqrt{2}} \cdot \frac{\cos \left(\frac{\alpha+\beta}{2}\right)}{\cos \left(\frac{\alpha-\beta}{2}\right)} .
$$

Essa última expressão usaremos para simular o tempo de intersecção. Veja o Algoritmo 3.1. 


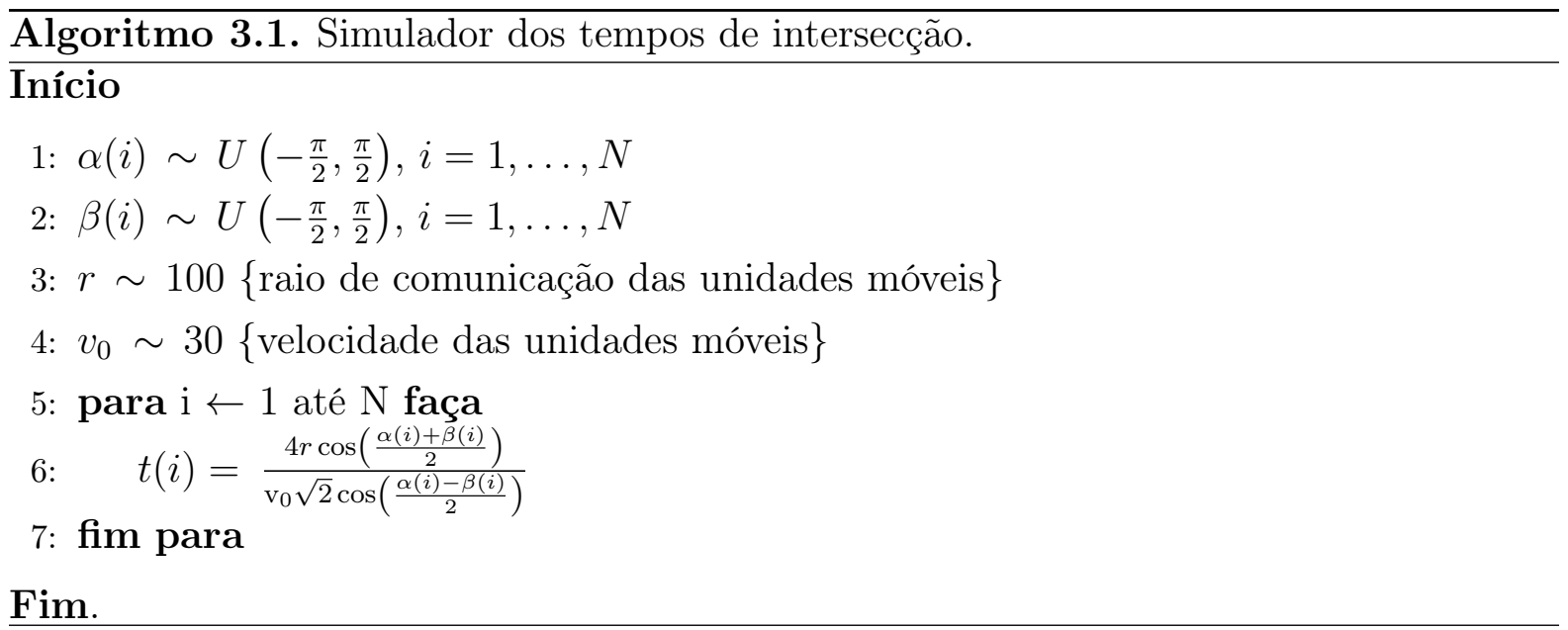

\subsubsection{Resultados da simulação}

Os resultados da simulação, veja Figura 3.6, mostram que os modelos map based movement e random waypoint apresentam comportamento semelhante às distribuições apresentadas em relação a densidade do tempo de intersecção $t_{\alpha, \beta}$.

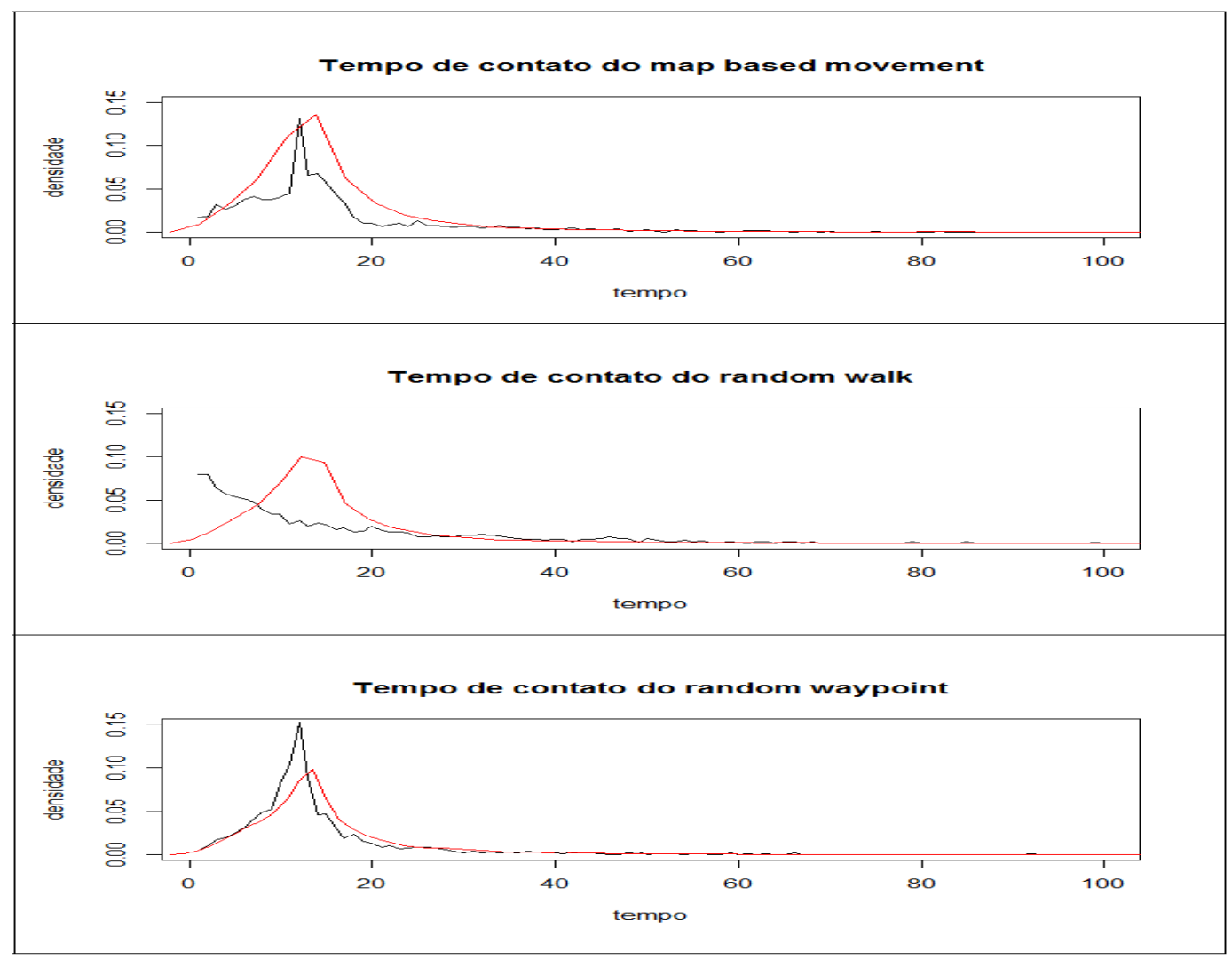

Figura 3.6: Resultados dos cenários de simulação de contatos dos modelos de mobilidade (map based movement, random walk e random waypoint). 
Isso significa que as intersecções nestes casos são parecidas com o esquema descrito acima. Enquanto o random walk representa a distribuição do tempo de intersecção completamente diferente, exponencial. Isso ocorre devido a intersecção do caso do random walk não ocorrer somente em uma direção, mas as direções mudam durante a intersecção várias vezes. 


\section{Capítulo 4}

\section{Grafo dinâmico como processo estocástico}

Neste Capítulo consideramos os modelos de mobilidades DTNs como processos estocásticos: processo de Markov e processo de renovação.

\subsection{Grafo dinâmico markoviano}

Naturalmente podemos representar os modelos de mobilidade como um processo de Markov conhecido como grafo aleatório dinâmico [HYPH15]. Para este processo de Markov, fornecemos o tempo médio da disseminação da informação de interesse comum (Information of Common Interest, IoCI).

Observamos que as conexões oportunistas realistas entre as unidades móveis (Mobile Units, $M U)$ podem ser consideradas como um processo estocástico de tempo contínuo $\mathcal{M}=\zeta(t)$ na topologia da rede de ecossistemas DTNs, com conjuntos dos estados serem uma posição de nós $V$ (MUs) em alguma área finita $A \subset \mathbb{R}^{2}$ que se move com algumas velocidades (definidas ou escolhidas aleatoriamente) em uma área $A$ de acordo com algum percurso, assim $\zeta(t) \in A^{|V|}$ ou $\zeta(t) \in \mathbb{R}^{2|V|}$.

Todos os nós possuem raio de enlace $r$, por isso se a distância entre dois nós quaisquer for menor que $2 r$, então a conexão entre estes nós ocorre. Se representamos uma conexão entre os nós como uma aresta em um grafo com o conjunto de vértices $V$, assim o processo $\mathcal{M}$ induz o então chamado grafo dinâmico de tempo contínuo $\mathcal{G}=\left\{G_{t}, t \in[0, \infty)\right\}$ de forma que o espaço de estados são todos os grafos possíveis com vértices $V$.

Observe que o grafo dinâmico $\mathcal{G}$ não é necessariamente um processo de Markov. Apesar do fato de que $\mathcal{G}$ não seja um processo de Markov, no caso quando a densidade dos nós na área $A$ for baixa a dinâmica do grafo $\mathcal{G}$ pode ser aproximada por um processo de Markov. Em particular, apresentamos a seguir o modelo de probabilidade proposto:

Observe que $V=\{1, \ldots, N\}$ seja novamente um conjunto de vértices, ou unidades móveis e $|V|=N$ seja a quantidade de nós em $V$. Para qualquer dois nós distintos $i, j$ 
$\in V, i \neq j$ associamos um processo de Markov de tempo contínuo $\xi_{i j}(t)$ com dois estados $\{0,1\}$ com taxas de transição:

$\lambda$ taxa de transição $0 \longrightarrow 1$ ("nascimento" de uma conexão),

$\mu$ taxa de transição $1 \longrightarrow 0$ ("morte" de uma conexão existente).

Todos os $\left(\xi_{i j}\right)_{i, j \in V}$ são independentes e identicamente distribuídos. Este processo de Markov é bem estudado e a distribuição de probabilidade para o processo $\xi_{i j}(t)$ está no estado $i \in\{0,1\}$ é conhecido explicitamente. Além disso, o regime estacionário para cada processo é dado pelo vetor $\pi_{i, j} \equiv \pi=(\pi(0), \pi(1))=\left(\frac{\mu}{\lambda+\mu}, \frac{\lambda}{\lambda+\mu}\right)$

Observe que o regime estacionário do grafo dinâmico $\mathcal{G}$ pode ser representado pelo famoso grafo aleatório de Erdös-Rényi $G(N, p)$ com o número de vértices $N$ e a probabilidade de se ter uma aresta entre dois vértices $p=\frac{\lambda}{\lambda+\mu}$. Neste contexto, observe que a duração dos contatos tem distribuição exponencial com taxa $\mu$. Isto é consequência da propriedade de Markov do nosso modelo, e está em conformidade com o resultado de [HYPH15], neste trabalho os autores mostraram que "a duração dos contatos entre um par de MUs obedece um modelo de mobilidade de direção aleatória é aproximadamente distribuída exponencialmente".

Quando $\lambda \ll \mu$ esperamos que o modelo reflita aproximadamente a comunicação oportunista entre os pares de usuários móveis (MUs) com dispositivos móveis equipados com grande capacidade de armazenamento e múltiplos modos de comunicação da rede em uma área com baixa densidade de MUs.

Usando a terminologia de [HYPH15] podemos formular o problema a ser resolvido para este caso. As MUs percorrem livremente a área finita $A$ e a "informação de interesse comum" (IoCI) é disseminada de acordo com o protocolo de retransmissão epidêmico. Nos termos da nossa definição de processo $\mathcal{M}$ pode ser formulado para alguns cenários:

1. quando um contato entre os nós $i, j \in V$ ocorre que, se o nó $i$ tem IoCI e $j$ não tem, então o nó $i$ passa (contamina) ao mesmo tempo o IoCI para o nó $j$.

2. assumindo que um IoCI possua tamanho $L$, então o IoCI passa através da conexão entre dois nós se o tempo de conexão é maior do que $L$, no modelo considerado ele passa com probabilidade $e^{\mu L}$

\subsubsection{Primeiro Cenário}

Suponha que no momento inicial o único nó 1 está contaminado (possui IoCI). O nó 1 com a taxa $(N-1) \lambda$ cria uma conexão e contamina com IoCI um novo nó $i_{1}$. Depois que um novo nó $i_{2}$ possa ser contaminado pelos dois nós 1 e $i_{1}$ com a taxa $2(N-2) \lambda$, etc. Se temos $k$ nós contaminados, então o novo nó contaminado aparece com a taxa $k(N-k) \lambda$, etc. Assim o tempo médio de atraso $T_{N}$ pode ser calculado como:

$$
T_{N}=\frac{1}{\lambda} \sum_{k=1}^{N-1} \frac{1}{k(N-k)}=\frac{1}{\lambda N} \sum_{k=1}^{N-1}\left(\frac{1}{k}+\frac{1}{N-k}\right)
$$


Que é igual a fórmula (7) em [HYPH15]. Além disso, se consideramos a assintótica tal que $\lambda N \longrightarrow c$ quando $N \longrightarrow \infty$, que corresponde a uma população com densidade pobre, então a assintótica da média do tempo de atraso total está crescendo como $\ln N$ :

$$
T_{N} \approx \frac{2}{c} \ln N \text { as } N \rightarrow \infty
$$

\subsubsection{Segundo Cenário}

No segundo cenário a taxa de um novo contato seria multiplicado pela probabilidade de passar a informação de um nó contaminado para um não contaminado. Isto significa que se temos $k$ nós contaminados, então o novo nó contaminado aparece com taxa $k(N-k) \lambda e^{\mu L}$, assim

$$
T_{N}=\frac{1}{\lambda e^{\mu L}} \sum_{k=1}^{N-1} \frac{1}{k(N-k)} \approx \frac{2 \ln N}{\lambda e^{\mu L}} \text { as } N \rightarrow \infty .
$$

As fórmulas (4.1.1) e (4.1.3) tem a mesma assintótica de $N$.

\subsection{Grafo dinâmico como processo de renovação}

Neste caso, quando o tempo de intercontatos e contatos não tem a distribuição exponencial, o modelo estocástico adequado para modelar as redes DTNs seria um processo de renovação.

Consideramos dois cenários:

1. Quando o tempo de contato é constante e igual a 1.

2. Quando o tempo de contato é uma variável aleatória.

Cenário 1. Definimos o processo $\xi(t)$ com dois estados 0 e 1 . Consideramos um conjunto de variáveis aleatórias discretas $\tau_{i}, \tau_{i} \geq 1$, independentes e identicamente distribuídas com a função de distribuição cumulativa $F_{0}$. Definimos as seguintes variáveis aleatórias $S_{n}=\sum_{k=1}^{n} \tau_{k}$. Então, o processo

$$
\xi(t)= \begin{cases}1, & \text { se existe } n \text { tal que } t=S_{n} \\ 0, & \text { caso contrário }\end{cases}
$$

é conhecido como processo de renovação.

Sabe-se que

$$
\lim _{t \rightarrow \infty} \mathbb{P}(\xi(t)=1)=\frac{1}{\mathbb{E}\left(\tau_{1}\right)} .
$$

Com cada par de vértices $i, j \in V$ associamos as cópias independentes do processo de renovação $\xi(t)$, denotando-os como $\xi_{i j}(t)$.

Interpretando, o evento $\left\{\xi_{i j}=1\right\}$ como a existência da conexão entre as unidades $i$, $j$ obtemos o grafo dinâmico $\mathcal{G}$. 
Observe que no limite, quando $t \rightarrow \infty$, o grafo dinâmico $\mathcal{G}$ pode ser representado pelo famoso grafo aleatório de Erdös-Rényi $G(N, p)$ com o número de vértices $N$ e a probabilidade de ter uma aresta entre dois vértices $p=\frac{1}{\mathbb{E}\left(\tau_{1}\right)}$.

Cenário 2. Para definir o segundo cenário introduzimos os tempos de contatos como variáveis aleatórias $\theta_{k}, \theta_{k} \geq 1$ independentes e identicamente distribuídas com função de distribuição cumulativa $F_{1}$. Introduzimos as seguintes variáveis aleatórias

$$
l_{n}=\sum_{k=1}^{n-1}\left(\tau_{k}+\theta_{k}\right)+\tau_{n}, \quad r_{n}=\sum_{k=1}^{n}\left(\tau_{k}+\theta_{k}\right) \text {. }
$$

Consideramos o seguinte processo

$$
\xi(t)= \begin{cases}1, & \text { se } l_{n}<t \leq r_{n} \\ 0, & \text { caso contrário. }\end{cases}
$$

Com cada par de vértices $i, j \in V$ associamos as cópias independentes do processo de renovação $\xi(t)$, denotando-os como $\xi_{i j}(t)$. Interpretando, o evento $\left\{\xi_{i j}=1\right\}$ como a existência da conexão entre as unidades $i, j$ e obtemos o grafo dinâmico $\mathcal{G}$.

Infelizmente, a análise do tempo médio de atraso não podemos calcular explicitamente no momento para grafos dinâmicos definidos pelos processos de renovação. Mas deixaremos o seguinte resultado como uma hipótese:

Quando $t \rightarrow \infty$ a medida invariante deste processo pode ser representado pelo famoso grafo aleatório de Erdös-Rényi $G(N, p)$ em que

$$
p=\frac{\mathbb{E}\left(\theta_{1}\right)}{\mathbb{E}\left(\theta_{1}\right)+\mathbb{E}\left(\tau_{1}\right)}
$$




\section{Capítulo 5}

\section{Métricas de redes complexas aplicadas no grafo dinâmico (evolução temporal)}

Consideremos como antes $G_{t}=\left(V, E_{t}\right)$ um snapshot no instante $t$ da sequência de grafos apresentada na definição de grafo dinâmico. Seja como antes $N=|V|$ o número de vértices e $m_{t}=\left|E_{t}\right|$ o número de arestas. Potencialmente $G_{t}=\left(V, E_{t}\right)$ não é conexo. Consideremos então que $G_{t}$ possui $c_{t}$ componentes conexas maximais. Aqui, chamamos de componentes conexas maximais uma componente conexa $C$ de $G_{t}$ tal que não existe $v \in V$ tal que $C^{\prime}=C \cup\{v\}$ seja conexa. Por questão de simplicidade, sempre que nos referirmos a componentes conexas de $G_{t}$, estaremos falando de componentes conexas maximais de $G_{t}$. Observe que se a quantidade de componentes conexas de $G_{t}$ for igual a $N$, então a rede está totalmente desconexa.

Consideremos ainda $\mathcal{C}_{t}^{\max }$ o conjunto das componentes conexas máxima de $G_{t}$, isto é, se $C \in \mathcal{C}_{t}^{\max }$ então a quantidade de vértices de $C$ é maior ou igual que qualquer outra componente conexa de $G_{t}$.

Apresentamos a seguir a definição das onze métricas de redes complexas para serem aplicadas sobre o conjunto de snapshots do grafo dinâmico de intervalo de tempo discreto.

1. Número de vértices $n_{t}^{C}$ de $C_{t} \in \mathcal{C}_{t}^{\max }$.

2. Número de arestas $m_{t}^{C}$ de $C_{t} \in \mathcal{C}_{t}^{\max }$.

3. Número de arestas $m_{t}$ de $G_{t}$.

4. Número de componentes conexas $c_{t}$ de $G_{t}$.

5. Número de componentes conexas máxima de $c_{t}^{\max }$.

6. Densidade: consideramos a densidade como sendo

$$
\rho_{t}=\frac{2 m_{t}}{N(N-1)}
$$


7. Grau médio de $G_{t}$ : o grau médio do grafo $G_{t}$ é dado por

$$
\bar{g}_{t}=\frac{\sum_{v \in V} g(v)}{N},
$$

em que $g(v)$ é o grau do vértice $v$.

8. Posto de $G_{t}$ : o posto de $G_{t}$, denotado por $r\left(G_{t}\right)$, é dado por

$$
r\left(G_{t}\right)=N-c_{t}
$$

em outras palavras o posto do grafo $G_{t}$ é igual ao número de vértices isolados.

9. Contato (conexão): é uma função booleana que possui valor 1 se existiu um enlace entre os nós $i$ e $j$ no instante de tempo $t$, e 0 , caso contrário.

10. Rota: é uma função booleana que possui valor 1 se existiu um caminho entre os nós $i$ e $j$ no instante de tempo $t$, e 0 , caso contrário.

11. Distância: $\mathrm{D}(i, j, t)$ é a menor distância (arestas) para ir do nó $i$ até o nó $j$ no instante de tempo $t$. Caso não exista uma rota, $\mathrm{D}(i, j, t)=\infty$.

A Figura 5.1 apresenta um exemplo de três snapshots de um grafo dinâmico de intervalo de tempo discreto.

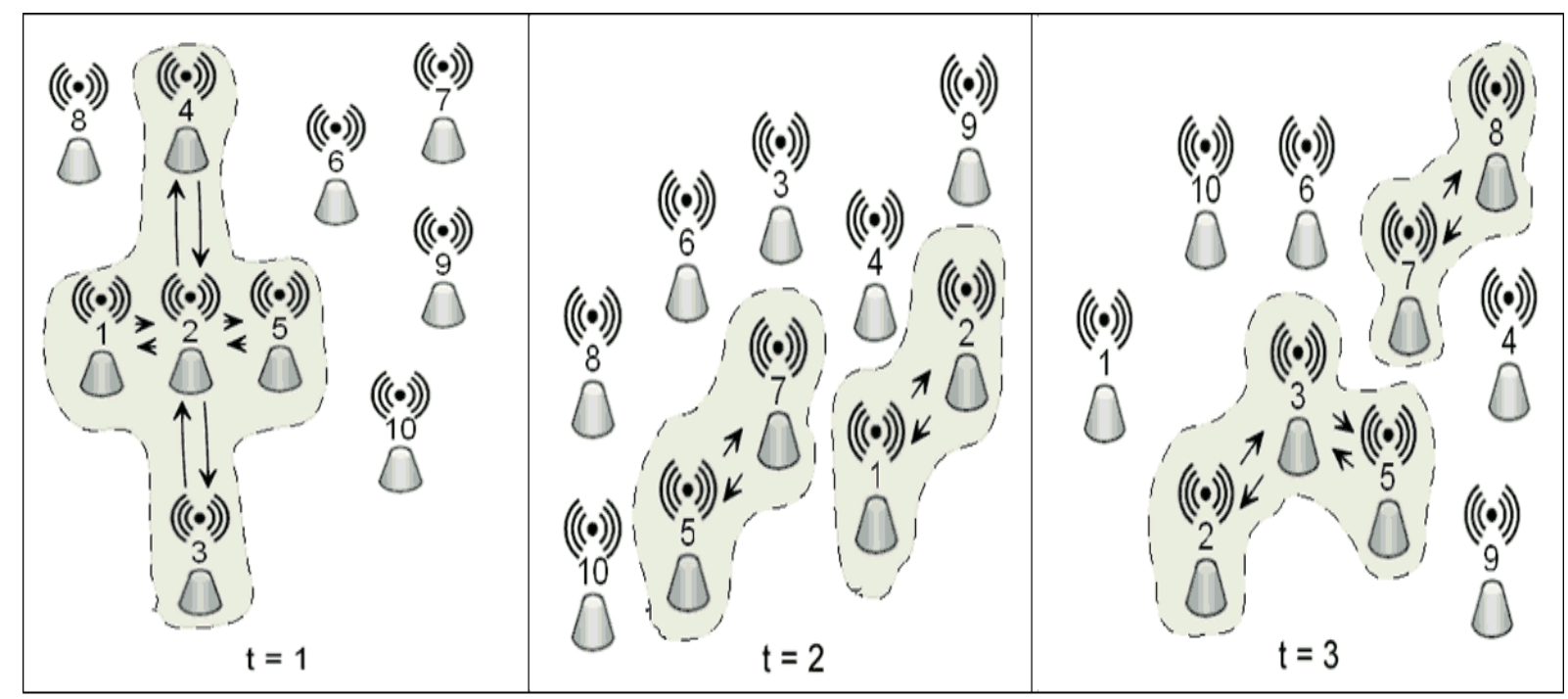

(a)

(b)

(c)

Figura 5.1: Exemplo de três snapshots de um grafo dinâmico de intervalo de tempo discreto.

A Tabela 5.1 apresenta os resultados dos cálculos da aplicação das métricas na Figura 5.1 são: 


\begin{tabular}{l|c|c|c|}
\hline Métricas do Arcabouço & $(\mathbf{a})$ & (b) & (c) \\
\hline Número de arestas & 8 & 4 & 6 \\
\hline Quantidade de componentes conexas & 6 & 8 & 7 \\
\hline $\begin{array}{l}\text { Quantidade de componentes conexas má- } \\
\text { xima }\end{array}$ & 1 & 2 & 1 \\
\hline $\begin{array}{l}\text { Quantidade de vértices na componente co- } \\
\text { nexa máxima }\end{array}$ & 5 & 2 & 3 \\
\hline $\begin{array}{l}\text { Quantidade de arestas na componente co- } \\
\text { nexa máxima }\end{array}$ & 8 & 4 & 4 \\
\hline Densidade & 0.1777 & 0.0888 & 0.1333 \\
\hline Grau médio & 1.6 & 0.8 & 1.2 \\
\hline Posto & 4 & 2 & 3 \\
\hline Valor do contato entre os nós 1 e 5 & 0 & 0 & 0 \\
\hline Valor da rota entre os nós 1 e 5 & 1 & 0 & 0 \\
\hline Distância entre os nós 1 e 5 & $\infty$ & $\infty$ \\
\hline
\end{tabular}

Tabela 5.1: Resultados dos cálculos da aplicação das métricas

A modelagem descritiva de grafo dinâmico de intervalo de tempo discreto é utilizada para tirar fotografias (snapshots) do ecossistema das redes DTNs e a instância deste modelo possibilita mapear a evolução temporal da mobilidade armazenada nos rastros de contatos relacionados com o conjunto de métricas apresentada na Tabela 5.1.

\subsection{Cenário de aplicação das métricas de redes com- plexas do grafo dinâmico}

Nesta seção analisamos de forma descritiva a evolução temporal das quatro métricas de grafos dinâmicos dos rastros de contatos dos modelos de mobilidade map based movement, random walk e random waypoint.

A Tabela 5.2 apresenta a configuração dos parâmetros do cenário para a aquisição dos rastros de contatos associados com os modelos de cenários de mobilidade map based movement, random walk e random waypoint:

\begin{tabular}{c|c}
\hline Descrição dos Parâmetros & Valor \\
\hline Semente & 1 \\
\hline Modelo de mobilidade & map based movement, random walk e random waypoint \\
\hline Número de nós & 50 \\
\hline Área & $4500 \mathrm{~m} \mathrm{x} 3400 \mathrm{~m}$ \\
\hline Raio & $100 \mathrm{~m}$ \\
\hline Velocidade & Ônibus $(30 \mathrm{~km} / \mathrm{h})$ \\
\hline Tempo de parada & $0 \mathrm{~s}$ \\
\hline
\end{tabular}

Tabela 5.2: Configuração dos parâmetros para os cenários de mobilidade Map Based Movement, Random Walk e Random Waypoint. 
Todos os modelos estocásticos do grafo dinâmico representados na Seção 4 têm uma particularidade em comum: as evoluções temporais de cada aresta são independentes. Isto é, a evolução temporal da conexão entre dois vértices $i$ e $j(i \neq j), \xi_{i, j}(t)$, é independente de $\xi_{k, l}(t)$ tal que o conjunto $\{k, l\} \neq\{i, j\}$. Por exemplo, a evolução $\xi_{1,5}(t)$ e a evolução $\xi_{3,8}(t)$ são independentes, do mesmo modo a evolução $\xi_{1,5}(t)$ e $\xi_{1,3}(t)$ são igualmente independentes.

Nesta seção, junto com a evolução temporal das métricas de grafos dinâmicos gerados pelo simulador The ONE consideramos a evolução das três métricas de grafos dinâmicos que chamamos de simulador independente. Este simulador usa como entrada a trajetória do grafo dinâmico $G_{t}$ gerado pelo The ONE, e mistura aleatoriamente os rótulos das arestas, usando permutação $\pi$, obtendo o grafo temporal $\pi\left(G_{t}\right)$.

O nosso objetivo é observar se existe diferença na estrutura das componentes conexas geradas pelo simulador The ONE e pelo simulador independente. O procedimento que descrevemos na estatística chama-se de teste de permutação. A hipótese (nula) que queremos testar é verificar se as evoluções de $\xi_{i, j}(t)$ simulados pelo The One são realmente independentes. A ideia do teste de permutação é a seguinte: misturando aleatoriamente os rótulos das arestas, $(i, j) \rightarrow \pi(i, j)$, em que $\pi$ é uma permutação aleatória dos rótulos, o simulador independente faz que todos os processos de evolução $\xi_{\pi(i, j)}(t)$ sejam realmente independentes. Desta forma, mantendo o mesmo número de arestas $m_{t}$ para a trajetória do The One, $G_{t}$, e a mesma trajetória depois da permutação dos rótulos, $\pi\left(G_{t}\right)$, calcularemos uma característica topológica e faremos a comparação entre a distribuição de valor da característica para a trajetória $G_{t}$ e a distribuição dela para a trajetória $\pi\left(G_{t}\right)$. Caso não observamos diferença significativa entre as duas distribuições, então aceitamos a hipótese nula sobre a independência dos processos $\xi_{i, j}(t)$, e a rejeitamos em caso contrário.

A Figura 5.2 apresenta a evolução temporal resultante da aplicação das métricas de redes complexas: número de componentes conexas $\left(c_{t}\right.$ - azul), número de componentes conexas máxima ( $c_{t}^{\text {max }}$ - laranja) e número de vértices na componente conexa máxima $\left(n_{t}^{c}\right.$ - vermelho ) no grafo dinâmico usando o simulador independente e o simulador The One para o modelo de mobilidade map based movement. 

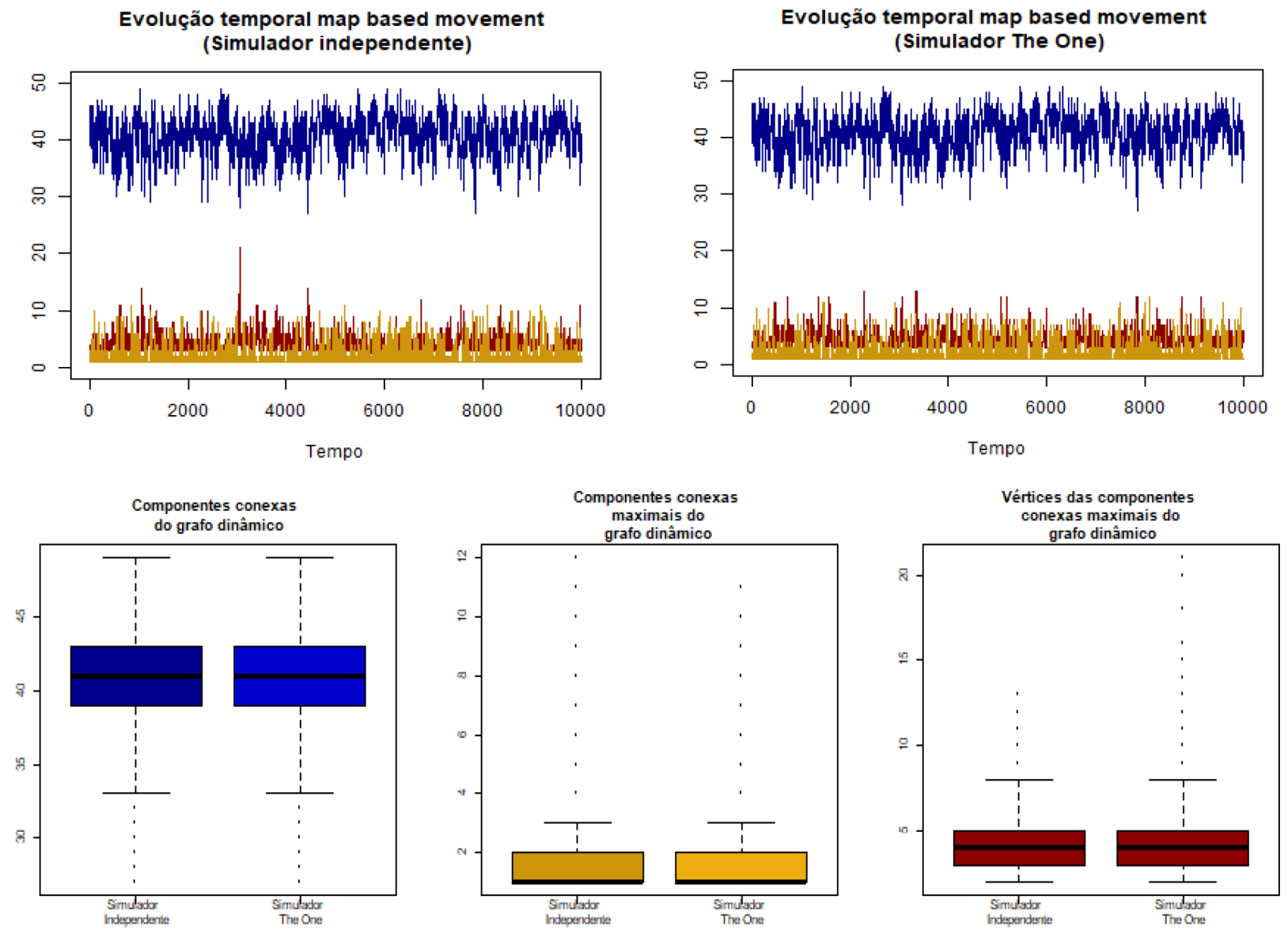

Figura 5.2: Evolução temporal da aplicação das métricas de redes complexas no grafo dinâmico usando o simulador independente e o simulador The One para o modelo de mobilidade map based movement.

Na Figura 5.2 constatamos que existe uma diferença imperceptível no comportamento da métrica relacionada com o número de componentes conexas $\left(c_{t}\right.$ - azul) do modelo de mobilidade map based movement. Embora a diferença nas outras características, $c_{t}^{\max } \mathrm{e}$ $n_{t}^{c}$ sejam mais evidentes nas trajetórias temporais as distribuições pelo boxplot são muito pequenas e insignificantes. Isto nos leva a aceitar a independência das trajetórias dos rastros de contatos.

A Figura 5.3 apresenta a evolução temporal resultante da aplicação das métricas de redes complexas: número de componentes conexas $\left(c_{t}\right.$ - azul), número de componentes conexas máxima ( $c_{t}^{\max }$ - laranja) e número de vértices na componente conexa máxima $\left(n_{t}^{c}\right.$ - vermelho ) no grafo dinâmico usando o simulador independente e o simulador The One para o modelo de mobilidade random walk. 
Evolução temporal random walk movement (Simulador independente)

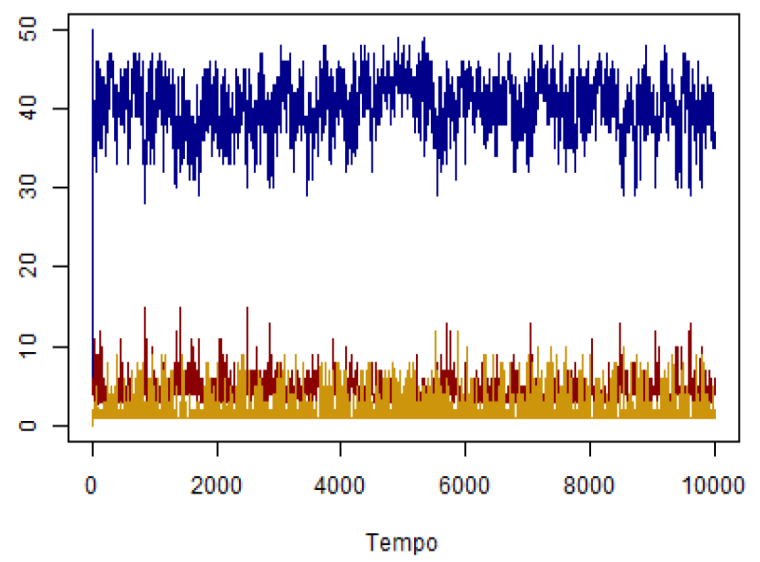

Evolução temporal random walk movement (Simulador The One)

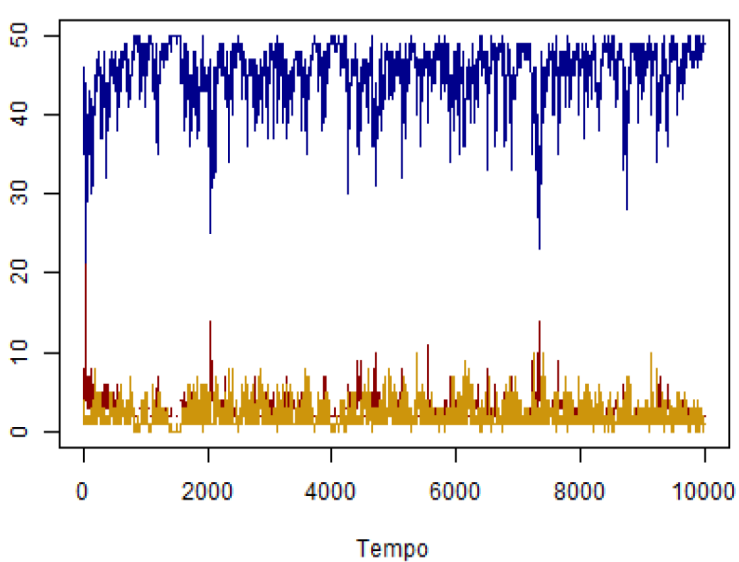

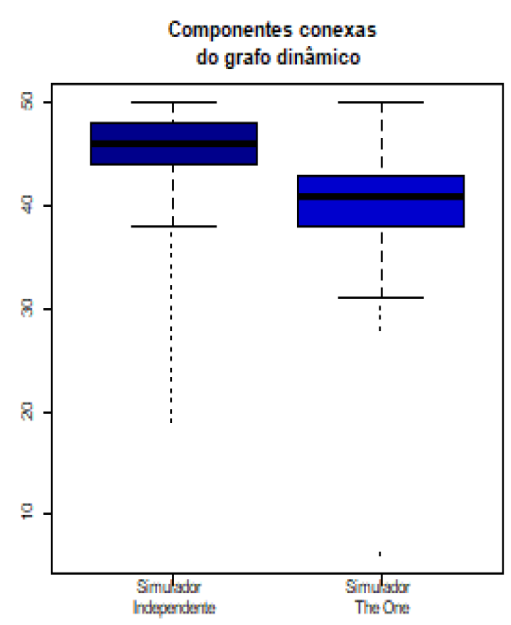
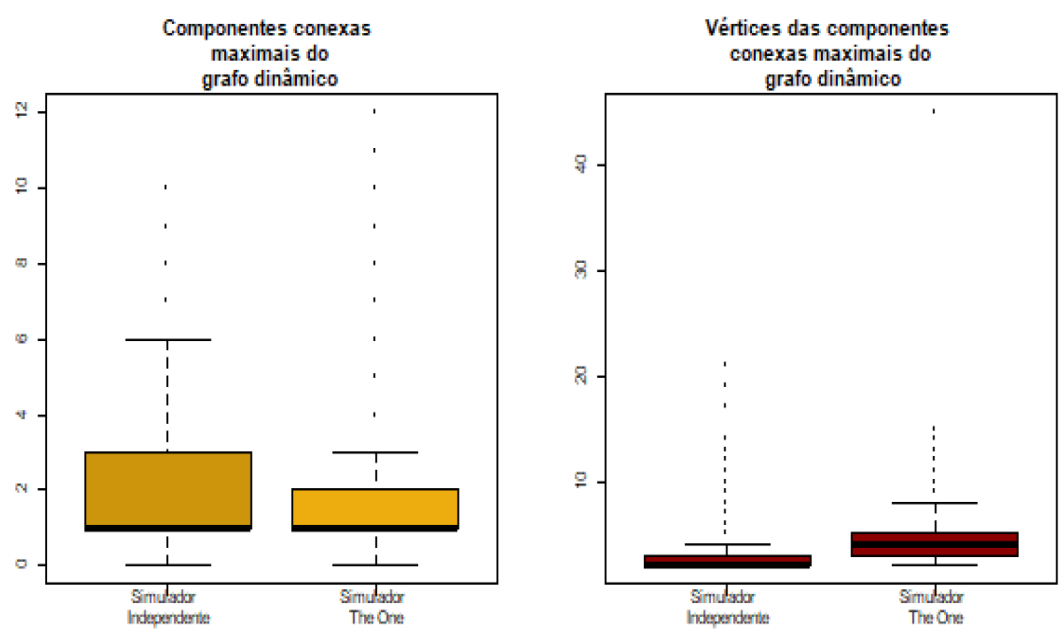

Figura 5.3: Evolução temporal da aplicação das métricas de redes complexas no grafo dinâmico usando o simulador independente e o simulador The One para o modelo de mobilidade random walk.

Na Figura 5.3 constatamos que as diferenças são significativas nos comportamentos das métricas relacionados com o número de componentes conexas, número de componentes conexas máxima e número de vértices na componente conexa máxima para o modelo de mobilidade random walk. No nível descritivo, isto nos leva a rejeitar a independência das trajetórias dos rastros de contatos.

A Figura 5.4 apresenta a evolução temporal resultante da aplicação das métricas de redes complexas: número de componentes conexas $\left(c_{t}-\right.$ azul), número de componentes conexas máxima ( $c_{t}^{\max }$ - laranja) e número de vértices na componente conexa máxima $\left(n_{t}^{c}\right.$ - vermelho ) no grafo dinâmico usando o simulador independente e o simulador The One para o modelo de mobilidade random waypoint. 


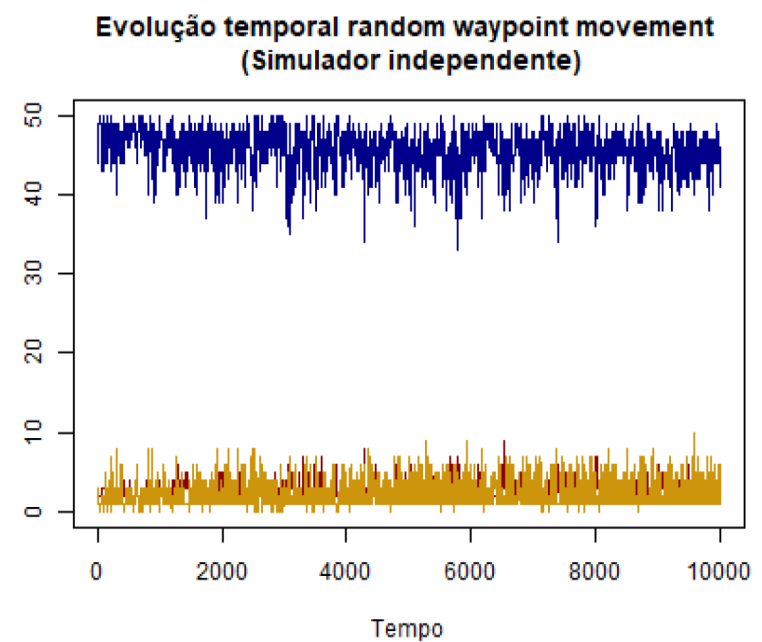

Evolução temporal random waypoint movement (Simulador The One)

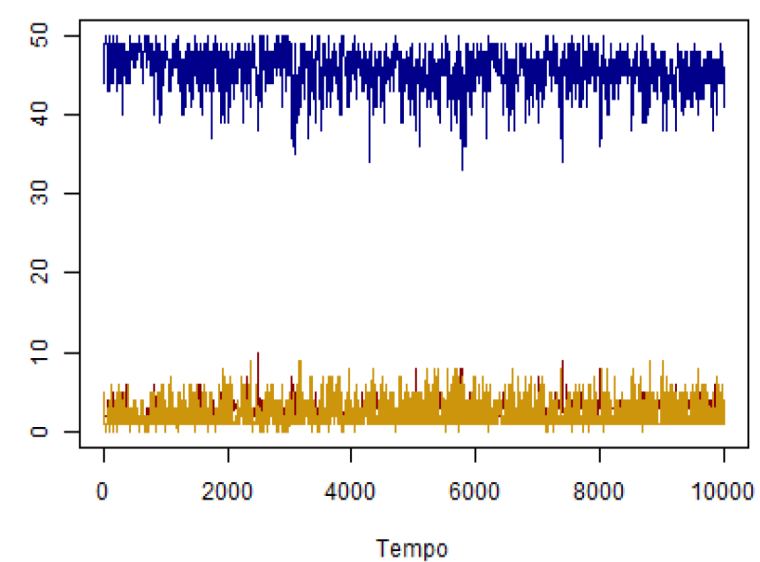

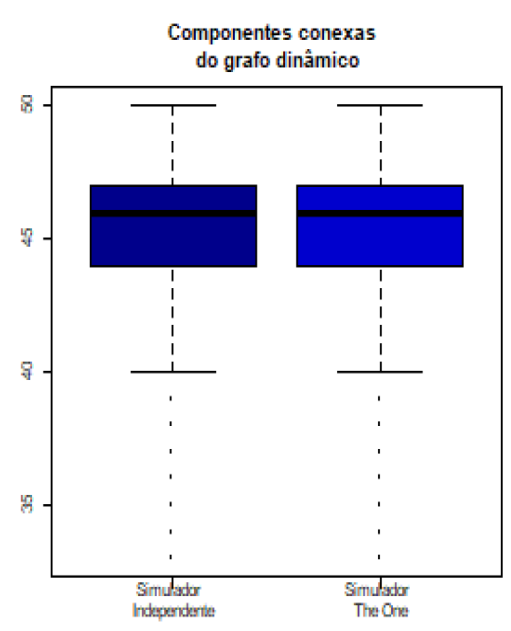
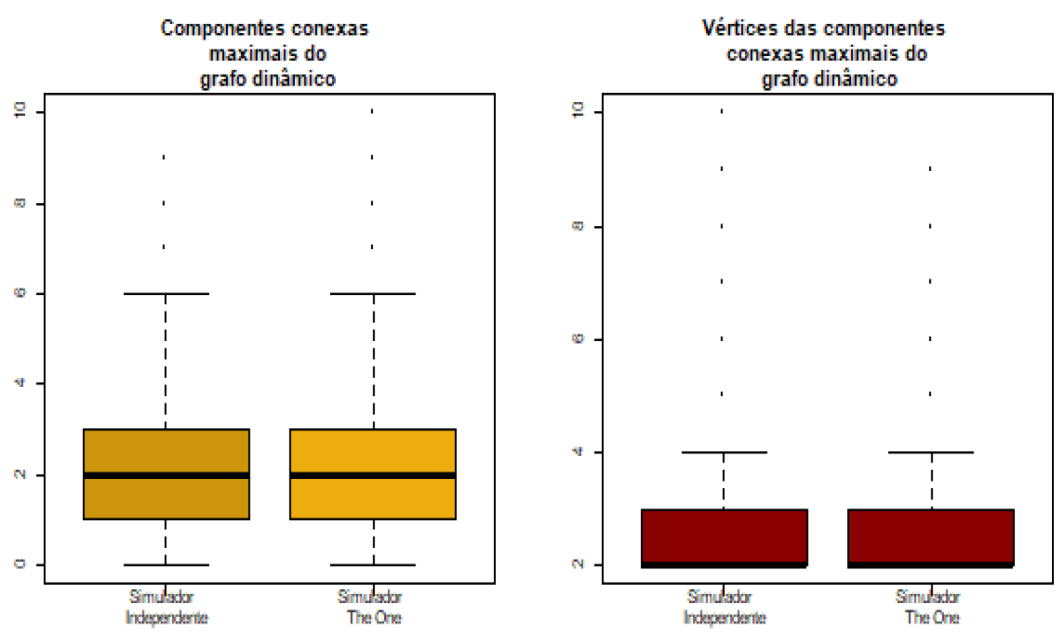

Figura 5.4: Evolução temporal da aplicação das métricas de redes complexas no grafo dinâmico usando o simulador independente e o simulador The One para o modelo de mobilidade random waypoint.

Na Figura 5.4 constatamos que existe uma diferença imperceptível no comportamento da métrica relacionada com o número de componentes conexas $\left(c_{t}\right.$ - azul) do modelo de mobilidade random waypoint. Embora a diferença nas outras características, $c_{t}^{\max }$ e $n_{t}^{c}$ sejam mais evidentes nas trajetórias temporais as distribuições pelo boxplot são muito pequenas e insignificantes. Isto nos leva a aceitar a independência das trajetórias dos rastros de contatos.

A análise estatística do comportamento individual das métricas de redes complexas aplicadas no grafo dinâmico é importante, no entanto em alguns casos não é suficiente devido a evolução temporal demandar a compreensão conjunta dos conjuntos das métricas apresentadas na Figura 5.2 . E este é um dos objetivos de estudos futuros. 
38 MÉTRICAS DE REDES COMPLEXAS APLICADAS NO GRAFO DINÂMICO (EVOLUÇÃO TEMPORAL) 


\section{Capítulo 6}

\section{Conclusão}

As informações relacionadas com o fenômeno da mobilidade em ecossistemas de redes DTNs é de natureza aleatória. Desta forma, o processo de aquisição de dados da mobilidade associados com o grafo dinâmico é importante para estabelecer a forma da distribuição das variáveis (atributos) que descrevem o fenômeno e os parâmetros da distribuição. Sermpezis e Spyropoulos [SS15] falam da ausência de um framework para estudar redes oportunistas. Então, o arcabouço que propomos contribui de forma efetiva para analisar ecossistemas de redes oportunistas.

Neste contexto, procuramos desenvolver diversos experimentos com o propósito de garantir representatividade das amostras relacionadas com as características importantes das populações dos modelos de mobilidade (map based movement, random walk e random waypoint). O modelo de grafo dinâmico e a especificação da arquitetura do arcabouço de redes complexas sistematizaram o processo de aquisição de dados dos rastros de contatos relacionado com as variações da topologia das redes de ecossistemas DTNs, e consequentemente possibilitou desenvolver a análise exploratória dos dados de contatos.

Primeiramente, investigamos a sensibilidade da parametrização dos atributos (sementes, velocidade, tempo de parada, raio de comunicação, quantidade de nós) dos cenários de mobilidade (map based movement, random walk e random waypoint) e consequentemente a sua simulação com o The One gerou os rastros de contatos associado com os encontros oportunistas entre as unidades móveis. Os resultados da análise estatística mostraram que todos os atributos são relevantes em ecossistemas DTNs, com exceção da semente.

Uma das mais importantes métricas dos modelos de mobilidade são os tempos de intercontatos. Os resultados da simulação e a análise exploratória mostraram que o modelo random waypoint apresenta distribuição exponencial do tempo de contato, random walk apresenta aparentemente comportamento polinomial, enquanto o map based movement tem característica dicotômica: até um determinado instante de tempo é polinomial e depois apresenta decaimento exponencial. Mesmo que o random walk mostre decaimento polinomial, os argumentos teóricos e simulação levam-nos a acreditar que o cenário poli- 
nomial é muito pessimista.

Foram consideradas outras métricas relacionadas com a topologia dos contatos: número de componentes conexas, número de componentes conexas máxima, número de vértices na componente conexa máxima.

Os gráficos da evolução temporal das métricas foram construídos e obtidos para cada cenário de mobilidade (map based movement, random walk e random waypoint).

Os resultados mostraram a aceitação da independência das trajetórias dos rastros de contatos para os cenários map based movement e random waypoint, e a rejeição da independência das trajetórias dos rastros de contatos para o cenários random walk.

Por último, representamos dois modelos de mobilidade de Markov de grafos dinâmicos e calculamos analiticamente o tempo médio de disseminação da informação.

Acreditamos, que os processos de Markov são adequados para os modelos de modelos de mobilidade do tipo random waypoint. Enquanto, para os outros modelos de mobilidade os processos de renovação podem ser mais apropriados.

\subsection{Trabalhos Futuros}

Durante o desenvolvimento da pesquisa, identificamos algumas questões que poderão ser desenvolvidas em trabalhos futuros como extensão deste. Elencamos a seguir as questões:

- Publicar em veículos científicos nacionais ou internacionais os resultados parciais da nossa pesquisa.

- Desenvolver uma análise com mais acurácia de todas as métricas que pesquisamos no contexto de ecossistemas de redes DTNs.

- Formalizar matematicamente os modelos analíticos que auxiliam a análise da evolução temporal das métricas de ecossistemas de redes DTNs.

- Analisar ecossistemas oportunistas com maior densidade de nós utilizando o formalismo matemático de grafos dinâmicos.

- Investigar outros modelos de mobilidade reais ou sintéticos relacionados com redes oportunistas.

- Pesquisar sobre a Técnica de Clumping em ecossistemas de redes DTNs [Ald89]. 


\section{Referências Bibliográficas}

[Ald89] D.J. Aldous. Probability Approximations Via the Poisson Clumping Heuristic. Applied mathematical sciences. Springer-Verlag, 1989. 40

[CBD02] Tracy Camp, Jeff Boleng e Vanessa Davies. A survey of mobility models for ad hoc network research. Wireless Communications and Mobile Computing, $2(5): 483-502,2002.10$

[CFQS12] Arnaud Casteigts, Paola Flocchini, Walter Quattrociocchi e Nicola Santoro. Time-varying graphs and dynamic networks. IJPEDS, 27(5):387-408, 2012. 11

$\left[\mathrm{CHC}^{+} 07\right]$ Augustin Chaintreau, Pan Hui, Jon Crowcroft, Christophe Diot, Richard Gass e James Scott. Impact of human mobility on opportunistic forwarding algorithms. IEEE Transactions on Mobile Computing, 6(6):606-620, 2007. 14

[CKNP15] Arnaud Casteigts, Ralf Klasing, Yessin M Neggaz e Joseph G Peters. Efficiently testing t-interval connectivity in dynamic graphs. Em Algorithms and Complexity, páginas 89-100. Springer, 2015. 2, 11

[CR13] Regin Cabacas e In-ho Ra. Evaluating mobility models in delay tolerant network. Em IT Convergence and Security (ICITCS), 2013 International Conference on, páginas 1-4. IEEE, 2013. 2, 7, 10

[CS13] Yue Cao e Zhili Sun. Routing in delay/disruption tolerant networks: A taxonomy, survey and challenges. Communications Surveys $\&$ Tutorials, IEEE, 15(2):654-677, 2013. 2

[dSBHO15] Aloizio Pereira da Silva, Scott Burleigh, Celso Massaki Hirata e Katia Obraczka. Dtn congestion control unplugged: A comprehensive performance study. Em Proceedings of the 10th ACM MobiCom Workshop on Challenged Networks, páginas 43-48. ACM, 2015. 2, 7, 10

[Fel68] William Feller. An introduction to probability theory and its applications: volume I, volume 3. John Wiley \& Sons New York, 1968. 19

[FF08] Kevin Fall e Stephen Farrell. Dtn: an architectural retrospective. Selected Areas in Communications, IEEE Journal on, 26(5):828-836, 2008. 2, 10

[HS13] P. Holme e J. Saramäki. Temporal Networks. Understanding Complex Systems. Springer Berlin Heidelberg, 2013. 12 
[HYPH15] J. Hu, L. L. Yang, H. V. Poor e L. Hanzo. Bridging the social and wireless networking divide: Information dissemination in integrated cellular and opportunistic networks. IEEE Access, 3:1809-1848, 2015. 27, 28, 29

[Jai91] R. Jain. The Art of Computer Systems Performance Analysis: Techniques for Experimental Design, Measurement, Simulation, and Modeling. Wiley professional computing. Wiley, 1991. 7

[KAF12] Maurice J Khabbaz, Chadi M Assi e Wissam F Fawaz. Disruption-tolerant networking: A comprehensive survey on recent developments and persisting challenges. Communications Surveys \&f Tutorials, IEEE, 14(2):607-640, 2012. 2,10

[KBV10] T. Karagiannis, J. Y. Le Boudec e M. Vojnovic. Power law and exponential decay of intercontact times between mobile devices. IEEE Transactions on Mobile Computing, 9(10):1377-1390, Oct 2010. 14, 16, 20

[KKO10] Ari Keränen, Teemu Kärkkäinen e Jörg Ott. Simulating mobility and dtns with the one. Journal of Communications, 5(2):92-105, 2010. 7, 10

[KOK09] Ari Keränen, Jörg Ott e Teemu Kärkkäinen. The one simulator for dtn protocol evaluation. Em Proceedings of the 2nd international conference on simulation tools and techniques, página 55. ICST (Institute for Computer Sciences, Social-Informatics and Telecommunications Engineering), 2009. 7

[LMO11] J. Loo, J.L. Mauri e J.H. Ortiz. Mobile Ad Hoc Networks: Current Status and Future Trends. Taylor \& Francis, 2011. 1

[May12] C. Mayer. Hybrid Routing in Delay Tolerant Networks. KIT Scientific Publishing, feb 2012. 7

[Roy10] R.R. Roy. Handbook of Mobile Ad Hoc Networks for Mobility Models. SpringerLink : Bücher. Springer, 2010. 1

[San12] P. Santi. Mobility Models for Next Generation Wireless Networks: Ad Hoc, Vehicular and Mesh Networks. Wiley Series in Communications Technology. Wiley, 2012. 10

[SBP13] Subir Kumar Sarkar, T. G. Basavaraju e C. Puttamadappa. Ad Hoc Mobile Wireless Networks: Principles, Protocols And Applications. Taylor \& Francis, 2 edição, 2013. 1

[SGS15] K. Sinha, S.C. Ghosh e B.P. Sinha. Wireless Networks and Mobile Computing. Taylor \& Francis, 2015. 1

$\left[\mathrm{SQF}^{+}{ }^{11}\right]$ Nicola Santoro, Walter Quattrociocchi, Paola Flocchini, Arnaud Casteigts e Frédéric Amblard. Time-varying graphs and social network analysis: Temporal indicators and metrics. CoRR, abs/1102.0629, 2011. 11

[SS15] P. Sermpezis e T. Spyropoulos. Modelling and analysis of communication traffic heterogeneity in opportunistic networks. IEEE Transactions on Mobile Computing, 14(11):2316-2331, Nov 2015. 39 
[WGG10] Klaus Wehrle, Mesut Gnes e James Gross. Modeling and Tools for Network Simulation. Springer Publishing Company, Incorporated, 1st edição, 2010. 10

[Zha06] Zhensheng Zhang. Routing in intermittently connected mobile ad hoc networks and delay tolerant networks: overview and challenges. Communications Surveys Tutorials, IEEE, 8(1):24-37, oct 2006. 2 cabeçalho para os apêndices 
APÊNDICES 


\section{Apêndice 1. Resultados dos testes de sensibilidade com o simulador The One}

Apresentamos os resultados dos testes com algumas métricas de grafos dinâmicos são sensíveis com as mudanças nos parâmetros dos simuladores.

Os métodos paramétricos possibilitam configurar os atributos (parâmetros) dos cenários de mobilidade para investigar se a amostragem estatística segue uma distribuição conhecida, com predições sendo feitas na escala de intervalos de tempo. Quando os experimentos resultantes da análise estatística não são satisfeitos (livres de distribuição), os métodos não paramétricos devem ser usados.

O teste de hipótese é uma técnica estatística que usamos para realizar a inferência estatística sobre as distribuições dos dados com a finalidade de saber se estas distribuições tem a mesma média ou mediana e se esses conjuntos de dados têm a mesma variabilidade.

No desenvolvimento da análise usamos os métodos estatísticos que elencamos a seguir:

- Análise das distribuições e Box plot comparativos;

- Teste de Kruskal-Wallis: método estatístico não paramétrico que proporciona testar a hipótese sobre um conjunto de amostras com o objetivo de verificar se estas possuem a mesma distribuição. O teste de Kruskal-Wallis frequentemente é usado para testar a hipótese de que todas as amostras foram selecionadas de distribuição igual (são da mesma população) contra a hipótese alternativa de que ao menos duas das populações possuem funções de distribuições diferentes. O teste de Kruskal-Wallis se baseia nos postos dos conjuntos de experimentos de cada amostra.

$H_{0}$ : as amostras têm a mesma distribuição de valores.

$H_{1}$ : as amostras não têm a mesma distribuição de valores. 


\section{Resultados Obtidos da Mudança das Sementes}

A Tabela 1 apresenta a configuração dos parâmetros para os cenários MapBasedMovement, RandomWalk, RandomWaypoint. Na Tabela 1 o parâmetro tempo de parada

\begin{tabular}{c|c}
\hline Descrição dos Parâmetros & Valor \\
\hline Sementes & $1 / 2 / 3 / 4$ \\
\hline Modelo de mobilidade & mapbasedmovement, random walk e random waypoint \\
\hline Número de nós & 50 \\
\hline Área & $4500 \mathrm{~m} \times 3400 \mathrm{~m}$ \\
\hline Raio & $100 \mathrm{~m}$ \\
\hline Velocidade & $100 \mathrm{~s}$ \\
\hline Tempo de parada & onnibus $(30-70 \mathrm{~km} / \mathrm{h})$ \\
\hline
\end{tabular}

Tabela 1: Configuração dos parâmetros para os cenários MapBasedMovement, RandomWalk, Random Waypoint.

para o modelo de mobilidade Random Walk é sempre 0.

A conjectura que propomos sobre a variação das sementes apresentado no cenário da Tabela 1 é de que este atributo não seja relevante para influenciar as oportunidades dos encontros oportunistas relacionados com os modelos de mobilidade das unidades móveis dos ecossistemas das redes DTNs.

A análise exploratória dos dados (box plots) e das distribuições possibilitou-nos observar que nos modelos de mobilidade map based movement e random walk a nossa conjectura se confirmou.

Consideramos os cenários apresentados na Seção para analisar os resultados obtidos das distribuições relacionadas com as modificações das sementes dos experimentos que apresentamos a seguir.

\section{Mobilidade MapBasedMovement}

A Figura 1 apresenta as distribuições obtidas de quatro amostras do modelo de mobilidade map based movement. 


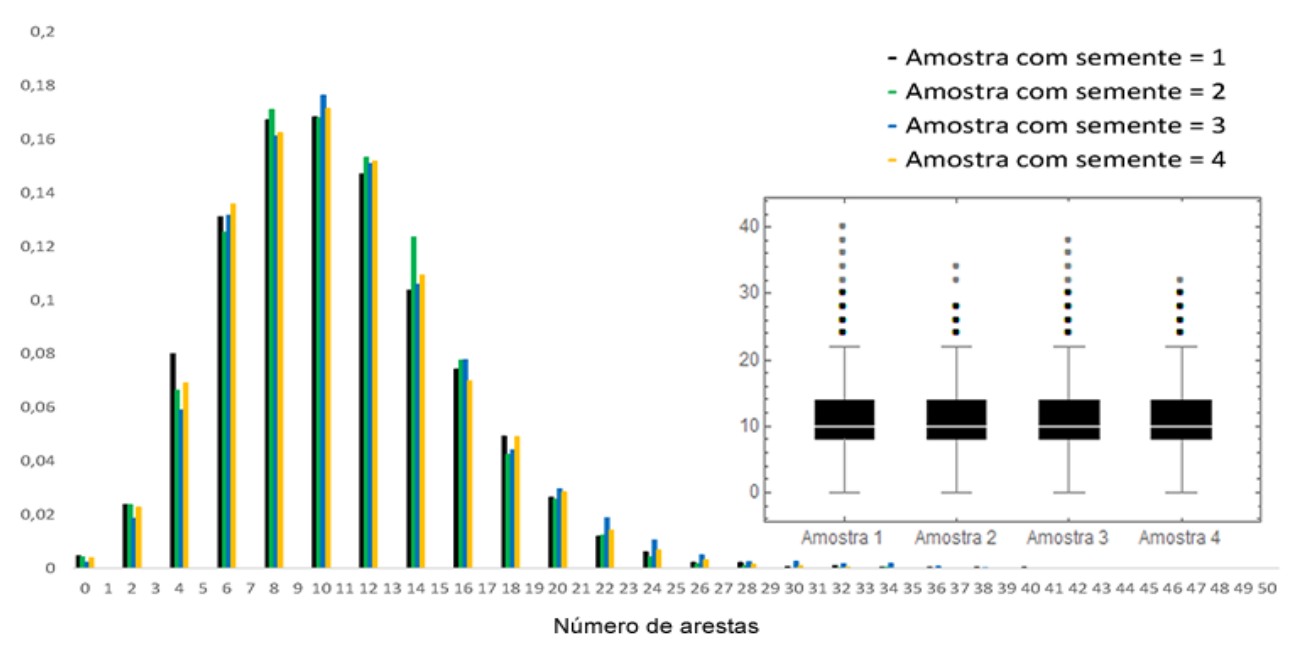

Figura 1: Distribuições obtidas de quatro amostras do modelo de mobilidade map based movement.

A análise das distribuições apresentadas na Figura 1 mostram que as mudanças das sementes nos cenários de mobilidade Map Based Movement não são relevantes para evidenciar a similaridade das amostras. O resultado do p-valor do teste foi igual aproximadamente a 1. Portanto, há evidências para afirmar que as distribuições não diferem significativamente.

\section{Mobilidade Random Walk}

A Figura 2 apresenta as distribuições obtidas de quatro amostras do modelo de mobilidade random walk.

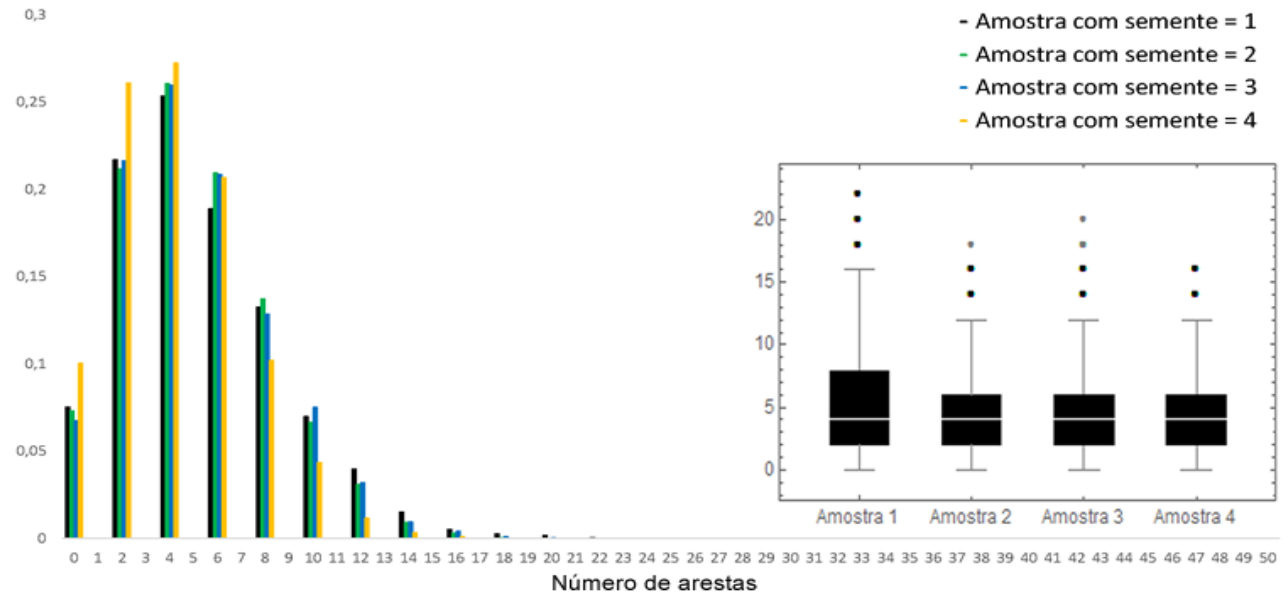

Figura 2: Distribuições obtidas de quatro amostras do modelo de mobilidade random walk. 
A análise das distribuições apresentadas na Figura 2 mostram que as mudanças das sementes nos cenários de mobilidade random walk não são relevantes para evidenciar a similaridade das amostras. O resultado do p-valor do teste foi aproximadamente igual a 1. Portanto, há evidências para afirmar que as distribuições não diferem significativamente.

\section{Mobilidade Random Waypoint}

A Figura 3 apresenta as distribuições obtidas de quatro amostras do modelo de mobilidade random waypoint.

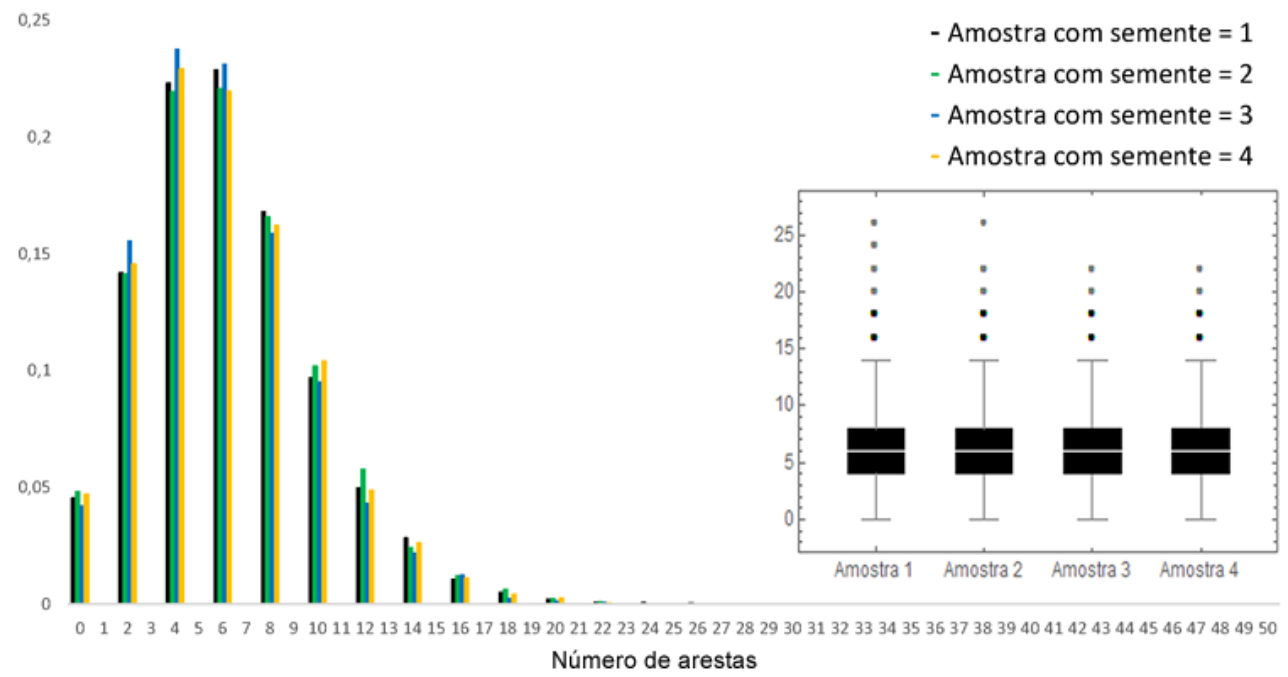

Figura 3: Distribuições obtidas de quatro amostras do modelo de mobilidade random waypoint.

A análise das distribuições apresentadas na Figura 3 mostram que as mudanças das sementes nos cenários de mobilidade random waypoint não são relevantes para evidenciar a similaridade das amostras. O resultado do p-valor do teste foi igual a aproximadamente 0.752. Portanto, há evidências para afirmar que as distribuições não diferem significativamente.

\section{Resultados Obtidos da Mudança dos Tempos de Paradas}

A Tabela 2 apresenta a configuração dos parâmetros para os cenários Map Based Movement, Random Walk e Random Waypoint: 


\begin{tabular}{c|c}
\hline Descrição dos Parâmetros & Valor \\
\hline Semente & 1 \\
\hline Modelo de mobilidade & map based movement, random walk e random waypoint \\
\hline Número de nós & 50 \\
\hline Área & $4500 \mathrm{~m} \mathrm{x} 3400 \mathrm{~m}$ \\
\hline Raio & $100 \mathrm{~m}$ \\
\hline Velocidade & ônibus $(30-70 \mathrm{~km} / \mathrm{h})$ \\
\hline Tempo de parada & $0,0 / 0,100 / 0,300 / 0,400 \mathrm{~s}$ \\
\hline
\end{tabular}

Tabela 2: Configuração dos parâmetros para os cenários Map Based Movement, Random Walk e Random Waypoint.

Na Tabela 2 o parâmetro tempo de parada para o modelo de mobilidade random Walk é sempre 0 .

A hipótese que propomos sobre a variação dos tempos de parada apresentado no cenário da Tabela 2 é de que este atributo é relevante para influenciar as oportunidades dos encontros oportunistas relacionados com os modelos de mobilidade das unidades móveis dos ecossistemas das redes DTNs.

A análise exploratória dos dados (box plots) e das distribuições possibilitou-nos observar que nos modelos de mobilidade map based movement e random walk a nossa conjectura foi confirmada.

Consideramos os cenários apresentados na Seção para analisar os resultados obtidos das distribuições relacionados com as modificações dos tempos de paradas dos nós dos cenários dos experimentos que apresentamos a seguir.

\section{Mobilidade MapBasedMovement}

A Figura 4 apresenta as distribuições obtidas de quatro amostras do modelo de mobilidade map based movement.

A análise das distribuições apresentadas na Figura 4 mostram que as mudanças dos tempos de paradas dos cenários de mobilidade map based movement são relevantes para evidenciar a similaridade das amostras. O resultado do p-valor do teste foi igual a aproximadamente 0. Portanto, há evidências para afirmar que as distribuições diferem significativamente. 


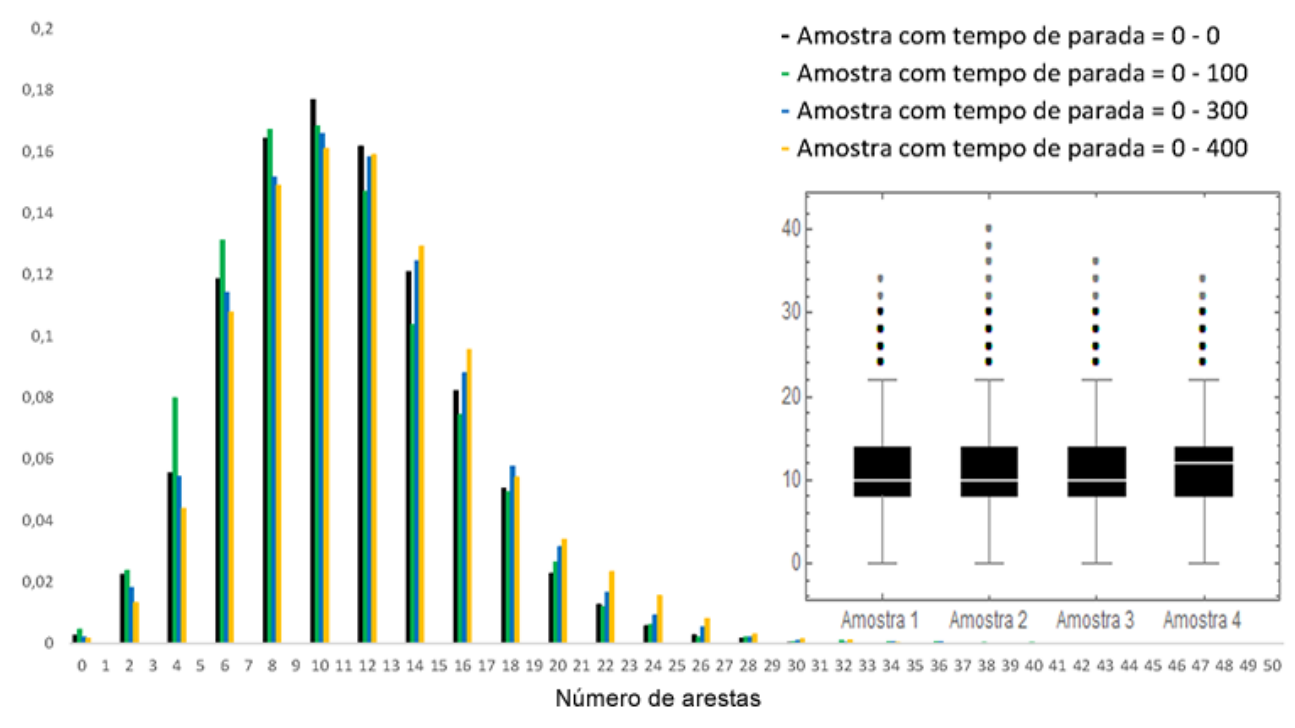

Figura 4: Distribuições obtidas de quatro amostras do modelo de mobilidade map based movement.

\section{Mobilidade Random Walk}

A Figura 5 apresenta as distribuições obtidas de quatro amostras do modelo de mobilidade random waypoint.

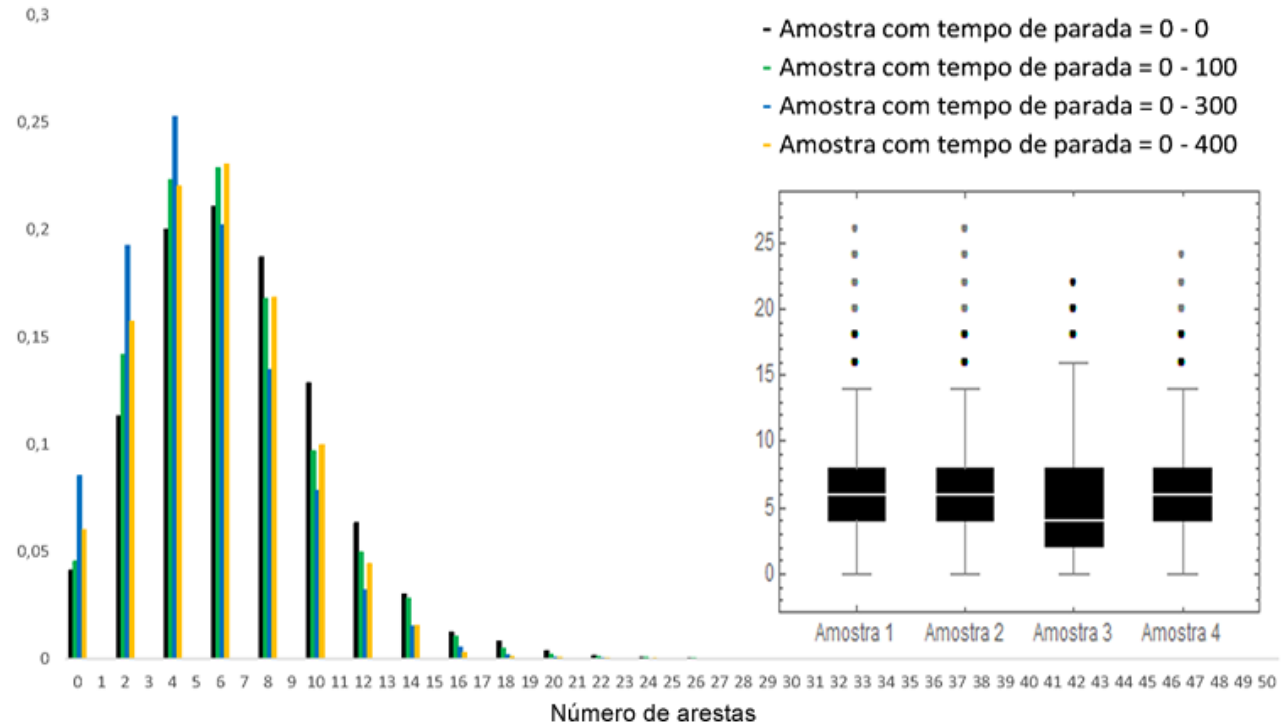

Figura 5: Distribuições obtidas de quatro amostras do modelo de mobilidade random waypoint.

A análise das distribuições apresentadas na Figura 5 mostram que as mudanças dos tempos de paradas dos cenários de mobilidade random waypoint são relevantes para evidenciar a similaridade das amostras. O resultado do p-valor do teste foi igual a apro- 
ximadamente 0. Portanto, há evidências para afirmar que as distribuições diferem significativamente.

\section{Resultados Obtidos da Mudança das Velocidades}

Consideramos os cenários apresentados na Seção 1 para analisar os resultados obtidos das distribuições relacionados com as mudanças das velocidades dos nós dos cenários dos experimentos que apresentamos a seguir.

A Tabela 3 apresenta a configuração dos parâmetros para os cenários Map Based Movement, Random Walk e Random Waypoint:

\begin{tabular}{c|l}
\hline Descrição dos Parâmetros & Valor \\
\hline Semente & 1 \\
\hline Modelo de mobilidade & map based movement, random walk e random waypoint \\
\hline Número de nós & 50 \\
\hline Área & $4500 \mathrm{~m} \times 3400 \mathrm{~m}$ \\
\hline Raio & $100 \mathrm{~m}$ \\
\hline Velocidade & Pedestre $(1,8-5,4 \mathrm{~km} / \mathrm{h}) /$ Corredor $(10-25 \mathrm{~km} / \mathrm{h}) /$ \\
& Bicicleta $(20-30 \mathrm{~km} / \mathrm{h}) /$ Onibus $(30-70 \mathrm{~km} / \mathrm{h})$ \\
\hline Tempo de parada & $0,100 \mathrm{~s}$ \\
\hline
\end{tabular}

Tabela 3: Configuração dos parâmetros para os cenários Map Based Movement, Random Walk e Random Waypoint.

A suposição que fazemos sobre mudanças nas velocidades apresentadas no cenário da Tabela 3 é de que este atributo é relevante para influenciar as oportunidades dos encontros oportunistas relacionados com os modelos de mobilidade das unidades móveis dos ecossistemas das redes DTNs. A análise exploratória dos dados (box plots) e das distribuições possibilitou-nos observar que em todos os modelos de mobilidade a nossa conjectura foi confirmada.

Na Tabela 3 o parâmetro tempo de parada para o modelo de mobilidade random walk é sempre 0 .

\section{Mobilidade MapBasedMovement}

A Figura 6 apresenta as distribuições obtidas de quatro amostras do modelo de mobilidade map based movement. 


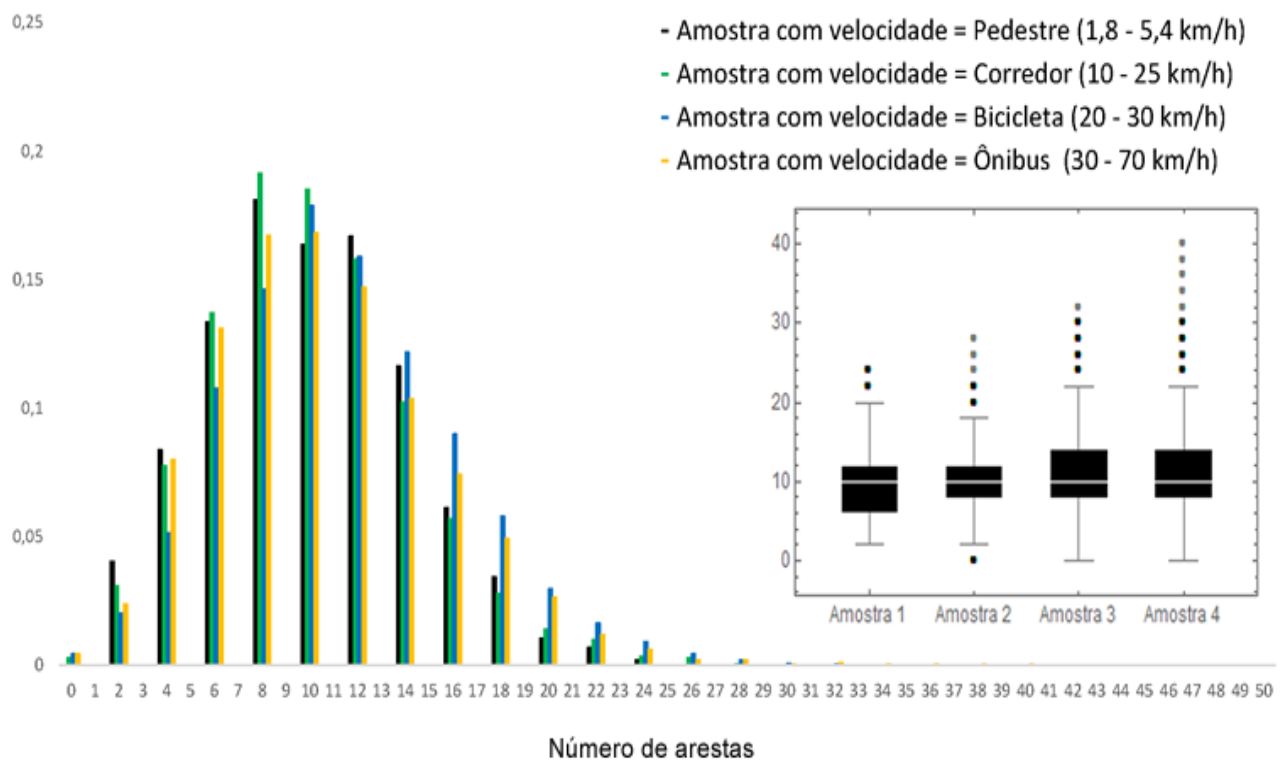

Figura 6: Distribuições obtidas de quatro amostras do modelo de mobilidade map based movement.

A análise das distribuições apresentadas na Figura 6 mostram que as mudanças na velocidade dos nós dos cenários de mobilidade map based movement são relevantes para evidenciar a similaridade das amostras. O resultado do p-valor do teste foi igual a aproximadamente 0. Portanto, há evidências para afirmar que as distribuições diferem significativamente.

\section{Mobilidade RandomWalk}

A Figura 7 apresenta as distribuições obtidas de quatro amostras do modelo de mobilidade random walk.

A análise das distribuições apresentadas na Figura 7 mostram que as mudanças nas velocidades dos nós dos cenários de mobilidade random walk são relevantes para evidenciar a similaridade das amostras. O resultado do p-valor do teste foi igual a aproximadamente 0. Portanto, há evidências para afirmar que as distribuições diferem significativamente. 


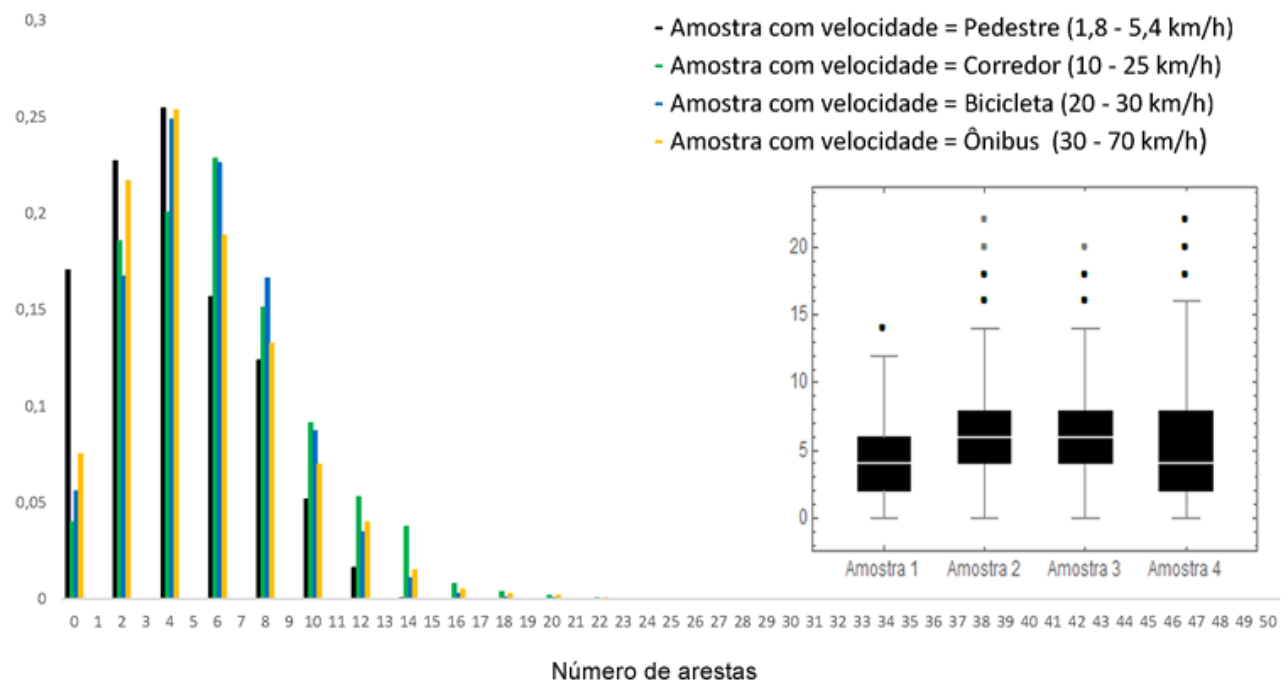

Figura 7: Distribuições obtidas de quatro amostras do modelo de mobilidade random walk.

\section{Mobilidade Random Waypoint}

A Figura 8 apresenta as distribuições obtidas de quatro amostras do modelo de mobilidade random waypoint.

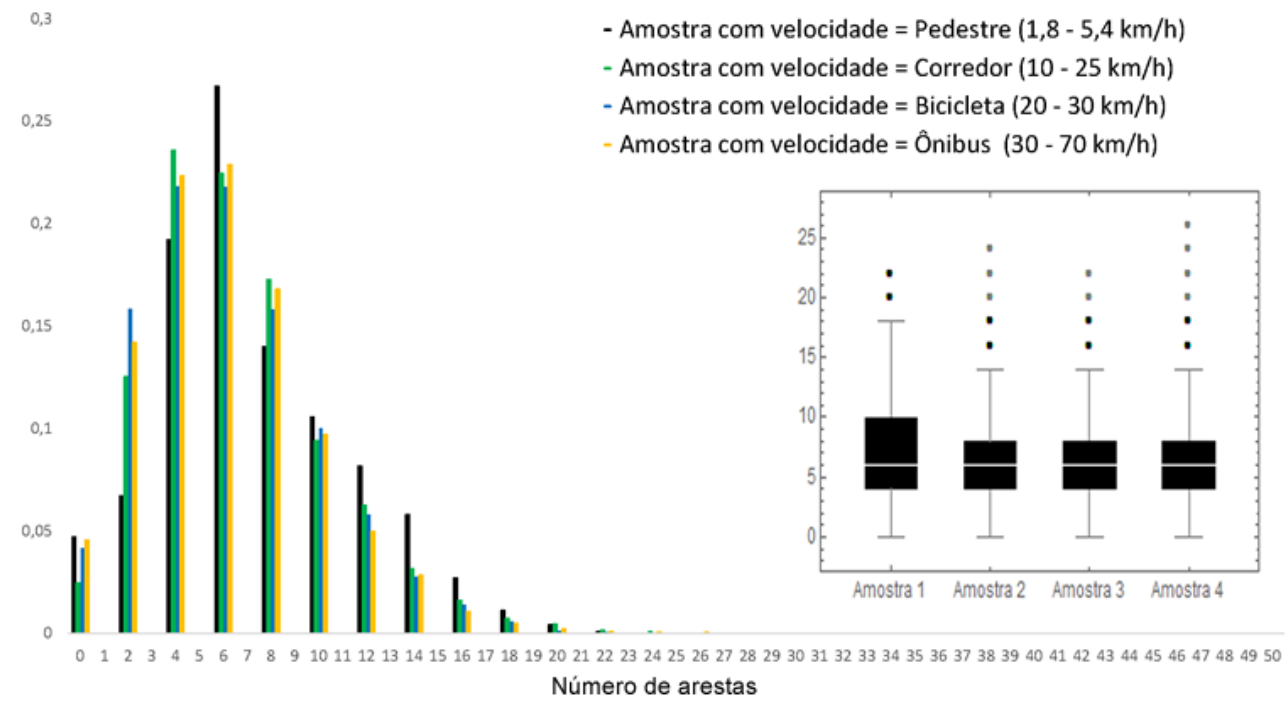

Figura 8: Distribuições obtidas de quatro amostras do modelo de mobilidade random waypoint.

A análise das distribuições apresentadas na Figura 8 mostram que as mudanças na velocidade dos nós dos cenários de mobilidade random waypoint são relevantes para evidenciar a similaridade das amostras. O resultado do p-valor do teste foi igual a apro- 
ximadamente 0. Portanto, há evidências para afirmar que as distribuições diferem significativamente.

\section{Resultados Obtidos da Mudança na Quantidade de Nós}

Consideramos os cenários apresentados na Seção 2 para analisar os resultados obtidos das distribuições relacionados com as modificações do número de nós dos cenários dos experimentos que apresentamos a seguir.

A Tabela 4 apresenta a configuração dos parâmetros para os cenários map based movement, random walk e random waypoint :

\begin{tabular}{c|c}
\hline Descrição dos Parâmetros & Valor \\
\hline Semente & 1 \\
\hline Modelo de mobilidade & map based movement, random walk e random waypoint \\
\hline Número de nós & $30 / 40 / 50 / 60$ \\
\hline Área & $4500 \mathrm{~m} \times 3400 \mathrm{~m}$ \\
\hline Raio & $100 \mathrm{~m}$ \\
\hline Velocidade & ïnibus $(30-70 \mathrm{~km} / \mathrm{h})$ \\
\hline Tempo de parada & $0,100 \mathrm{~s}$ \\
\hline
\end{tabular}

Tabela 4: Configuração dos parâmetros para os cenários map based movement, random walk e random waypoint.

Na Tabela 4 o parâmetro tempo de parada para o modelo de mobilidade random walk é sempre 0.

A conjectura que fazemos sobre mudanças nas quantidade de unidades móveis apresentadas no cenário da Tabela 4 é de que este atributo é relevante para influenciar as oportunidades dos encontros oportunistas relacionados com os modelos de mobilidade das unidades móveis dos ecossistemas das redes DTNs. A análise exploratória dos dados (box plots) e das distribuições possibilitou-nos observar que em todos os modelos de mobilidade a nossa hipótese foi confirmada. 


\section{Mobilidade MapBasedMovement}

A Figura 9 apresenta as distribuições obtidas de quatro amostras do modelo de mobilidade map based movement.

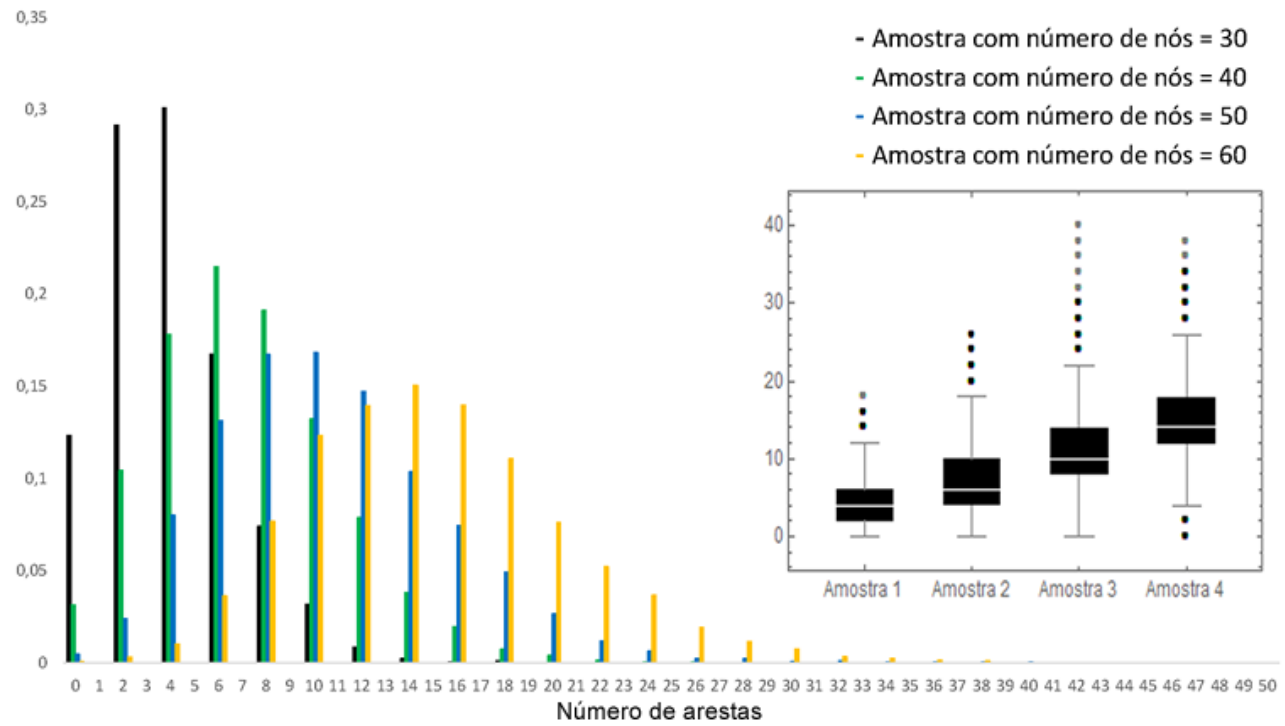

Figura 9: Distribuiçôes obtidas de quatro amostras do modelo de mobilidade map based movement.

A análise das distribuições apresentadas na Figura 9 mostram que as mudanças na quantidade de nós dos cenários de mobilidade map based movement são relevantes para evidenciar a similaridade das amostras. O resultado do p-valor do teste foi igual a aproximadamente 0. Portanto, há fortes evidências para afirmar que as distribuições diferem significativamente.

\section{Mobilidade Random Walk}

A Figura 10 apresenta as distribuições obtidas de quatro amostras do modelo de mobilidade random walk.

A análise das distribuições apresentadas na Figura 10 mostram que as mudanças na quantidade de nós dos cenários de mobilidade random walk são relevantes para evidenciar a similaridade das amostras. O resultado do p-valor do teste foi igual a aproximadamente 0. Portanto, há fortes evidências para afirmar que as distribuições diferem significativamente. 


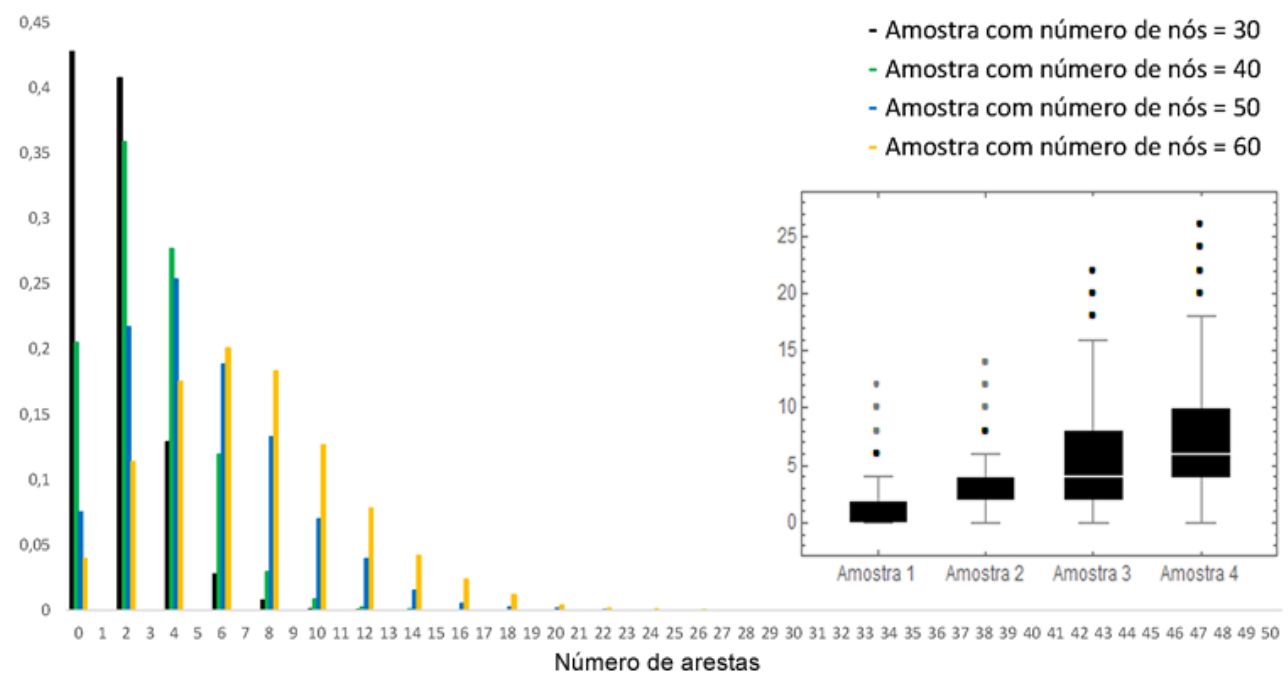

Figura 10: Distribuições obtidas de quatro amostras do modelo de mobilidade random walk.

\section{Mobilidade Random Waypoint}

A Figura 11 apresenta as distribuições obtidas de quatro amostras do modelo de mobilidade random waypoint.

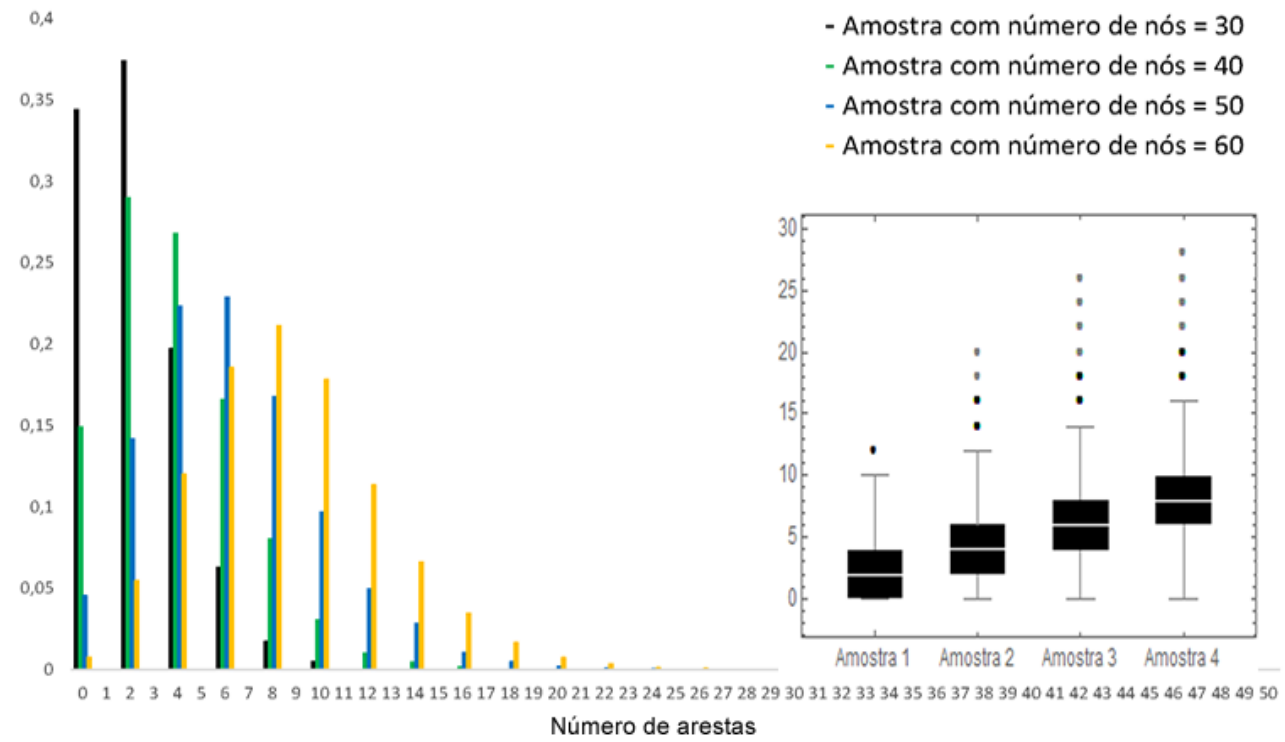

Figura 11: Distribuições obtidas de quatro amostras do modelo de mobilidade random waypoint.

A análise das distribuições apresentadas na Figura 11 mostram que as mudanças na quantidade de nós dos cenários de mobilidade random waypoint são relevantes para evidenciar a similaridade das amostras. O resultado do p-valor do teste foi igual a apro- 
ximadamente 0. Portanto, há fortes evidências para afirmar que as distribuições diferem significativamente.

\section{Resultados Obtidos da Mudança do Raio}

Consideramos os cenários apresentados na Seção 3 para analisar os resultados obtidos das distribuições relacionados com as modificações dos raios dos nós dos experimentos que apresentamos a seguir.

A Tabela 5 apresenta a configuração dos parâmetros para os cenários map based movement, random walk e random waypoint:

\begin{tabular}{c|c}
\hline Descrição dos Parâmetros & Valor \\
\hline Semente & 1 \\
\hline Modelo de mobilidade & map based movement, random walk e random waypoint \\
\hline Número de nós & 50 \\
\hline Área & $4500 \mathrm{~m} \mathrm{x} \mathrm{3400} \mathrm{m}$ \\
\hline Raio & $100 / 200 / 300 / 400 \mathrm{~m}$ \\
\hline Velocidade & ônibus $(30-70 \mathrm{~km} / \mathrm{h})$ \\
\hline Tempo de parada & $0,100 \mathrm{~s}$ \\
\hline
\end{tabular}

Tabela 5: Configuração dos parâmetros para os cenários Map Based Movement, Random Walk e Random Waypoint.

Na Tabela 5 o parâmetro tempo de parada para o modelo de mobilidade random Walk é sempre 0 .

A hipótese que fazemos sobre mudanças nos raios das unidades móveis apresentadas no cenário da Tabela 5 é de que este atributo é relevante para influenciar as oportunidades dos encontros oportunistas relacionados com os modelos de mobilidade das unidades móveis dos ecossistemas das redes DTNs. A análise exploratória dos dados (box plots) e das distribuições possibilitou-nos observar que em todos os modelos de mobilidade a nossa conjectura foi confirmada.

\section{Mobilidade MapBasedMovement}

A Figura 12 apresenta as distribuições obtidas de quatro amostras do modelo de mobilidade map based movement. 


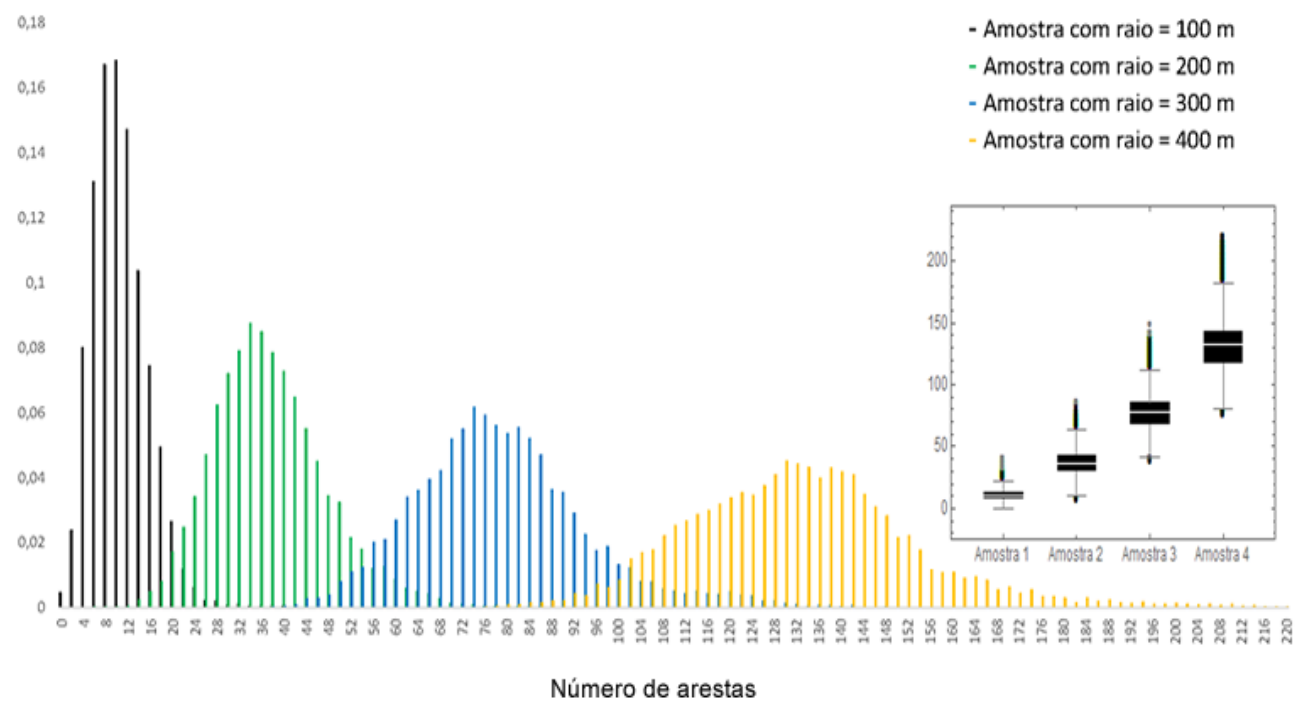

Figura 12: Distribuiçôes obtidas de quatro amostras do modelo de mobilidade map based movement.

A análise das distribuições apresentadas na Figura 12 mostram que as mudanças no raio dos nós dos cenários de mobilidade map based movement são relevantes para evidenciar a similaridade das amostras. O resultado do p-valor do teste foi igual a aproximadamente 0. Portanto, há fortes evidências para afirmar que as distribuições diferem significativamente.

\section{Mobilidade Random Walk}

A Figura 13 apresenta as distribuições obtidas de quatro amostras do modelo de mobilidade random walk.

A análise das distribuições apresentadas na Figura 13 mostram que as mudanças no raio dos nós dos cenários de mobilidade random walk são relevantes para evidenciar a similaridade das amostras. O resultado do p-valor do teste foi aproximadamente igual a 0. Portanto, há fortes evidências para afirmar que as distribuições diferem significativamente.

\section{Mobilidade Random Waypoint}

A Figura 14 apresenta as distribuições obtidas de quatro amostras do modelo de mobilidade random waypoint. 


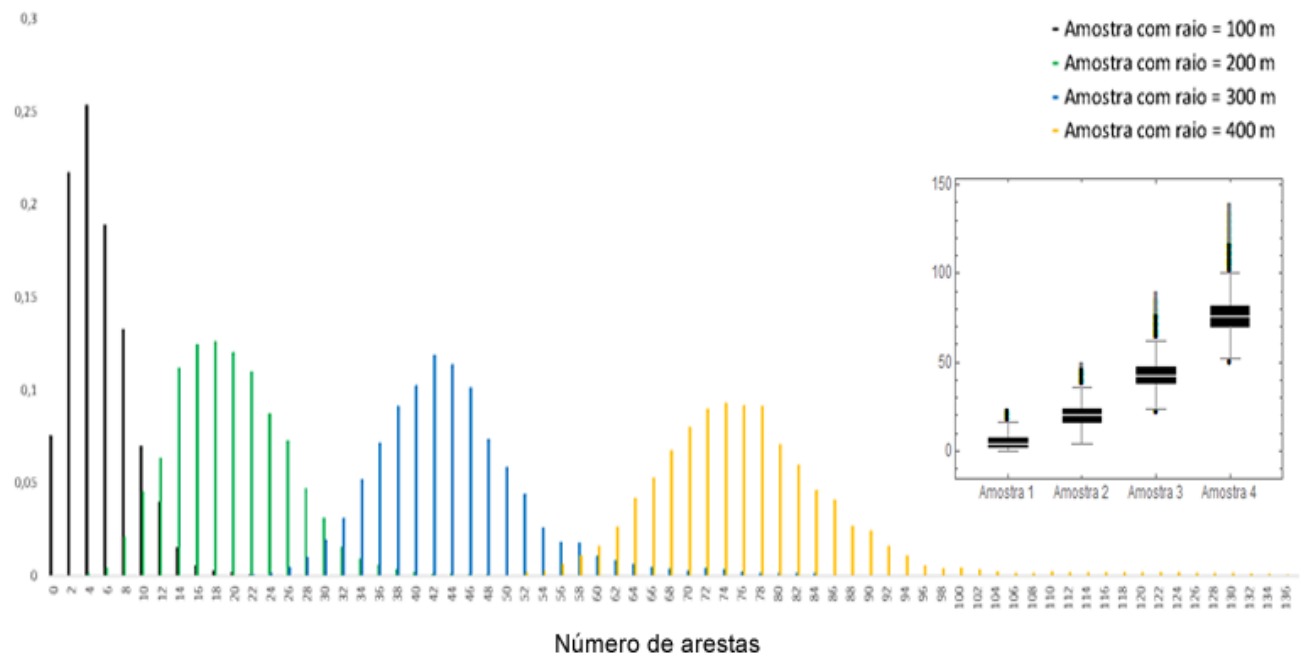

Figura 13: Distribuições obtidas de quatro amostras do modelo de mobilidade random walk.

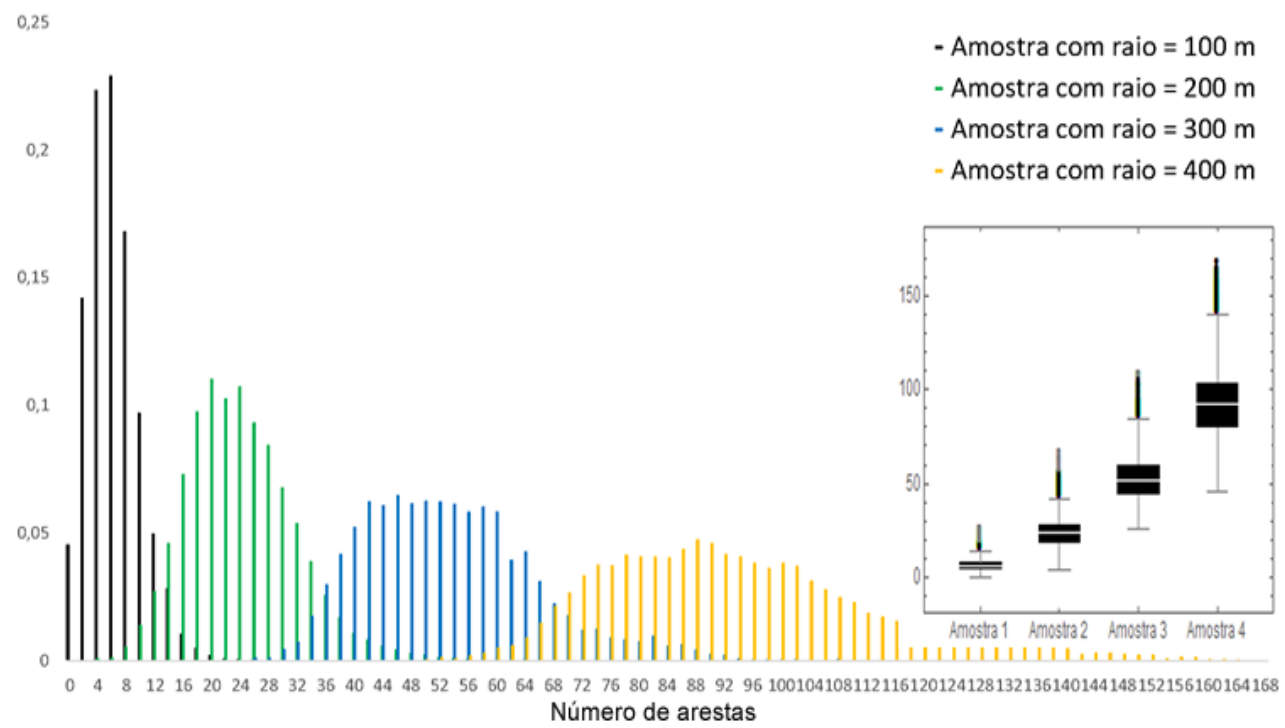

Figura 14: Distribuições obtidas de quatro amostras do modelo de mobilidade random waypoint.

A análise das distribuições apresentadas na Figura 14 mostram que as mudanças no raio dos nós dos cenários de mobilidade random waypoint são relevantes para evidenciar a similaridade das amostras. O resultado do p-valor do teste foi igual a aproximadamente 0 . Portanto, há fortes evidências para afirmar que as distribuições diferem significativamente. 


\section{Apêndice 2. Random walk no torus unidimensional}

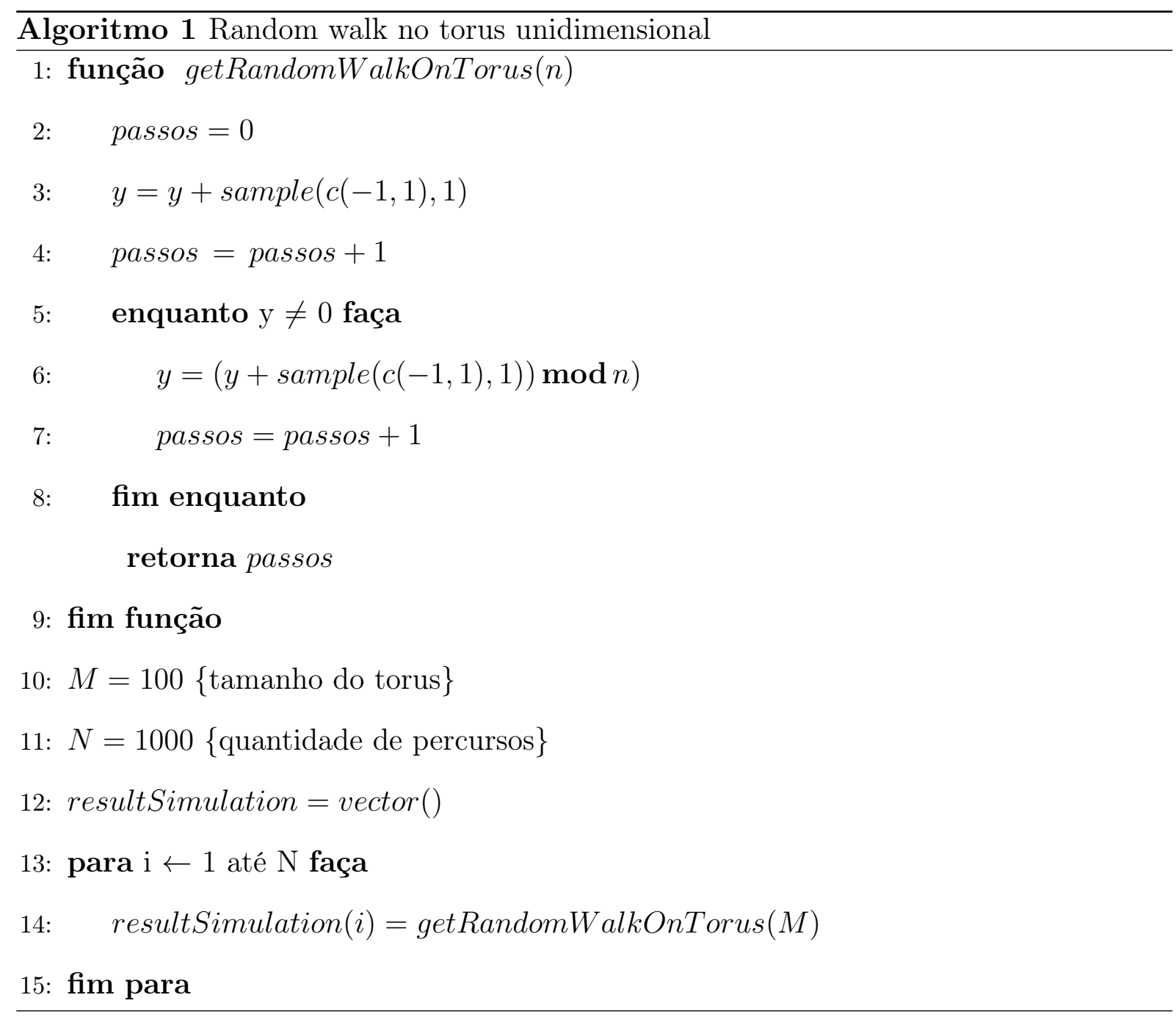




\section{Apêndice 3. Random walk no torus bidimensional}

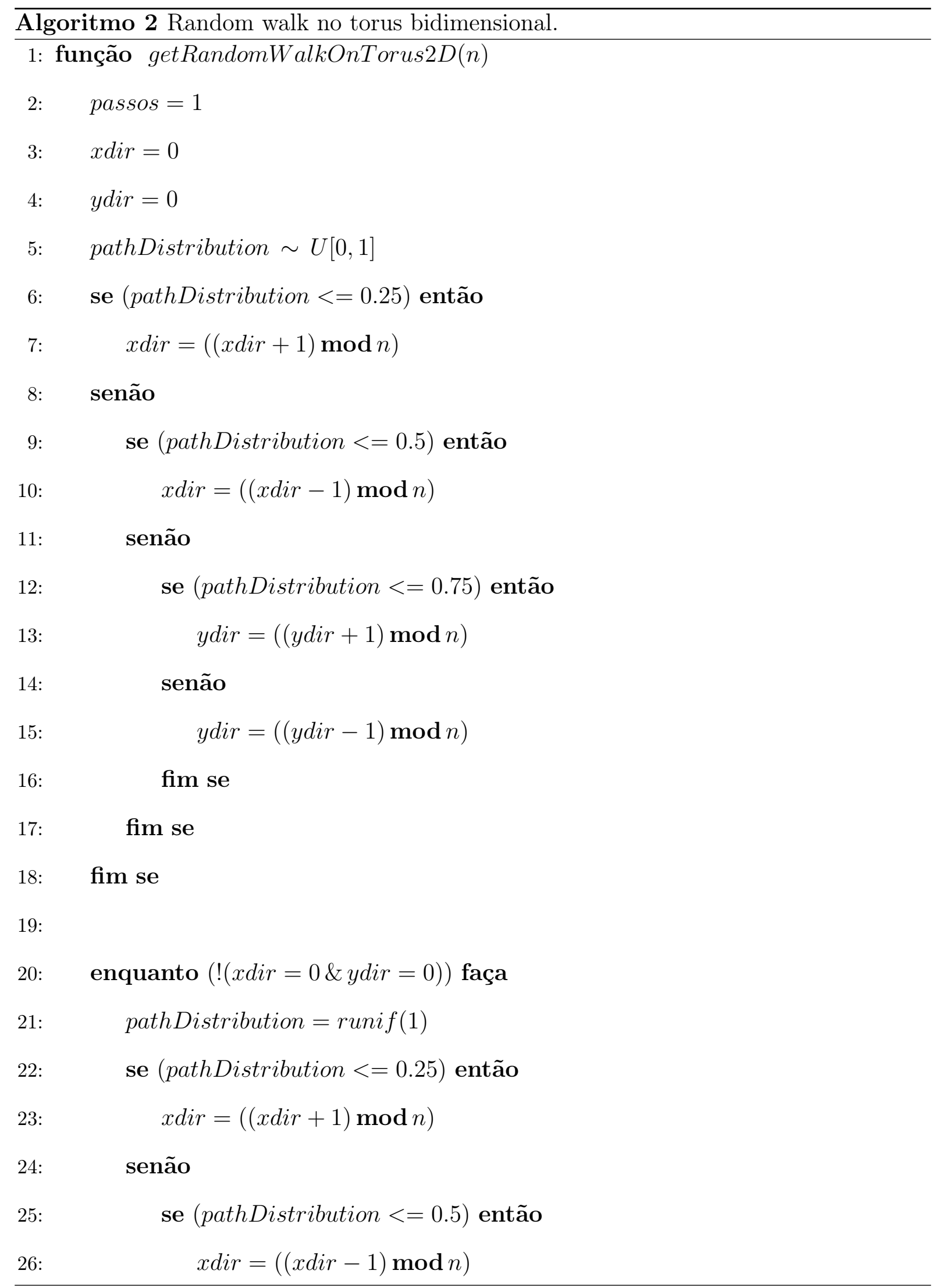


27:

28:

29:

30:

31:

32:

33:

34:

35:

36:

\section{senão}

se (pathDistribution $<=0.75)$ então

$$
y d i r=((y d i r+1) \bmod n)
$$

$$
\text { senão }
$$

$$
y d i r=((y d i r-1) \bmod n)
$$

fim se

fim se

fim se

$$
\text { passos }=\text { passos }+1
$$

\section{fim enquanto}

retorna passos

\section{7: fim função}

38: $M=100$ tamanho do torus

39: $N=1000$ \{quantidade de percursos\}

40: resultSimulation $=$ vector ()

41: para $\mathrm{i} \leftarrow 1$ até $\mathrm{N}$ faça

42: $\quad$ resultSimulation $(i)=\operatorname{getRandomWalkOnTorus} 2 D(M)$

43: fim para 